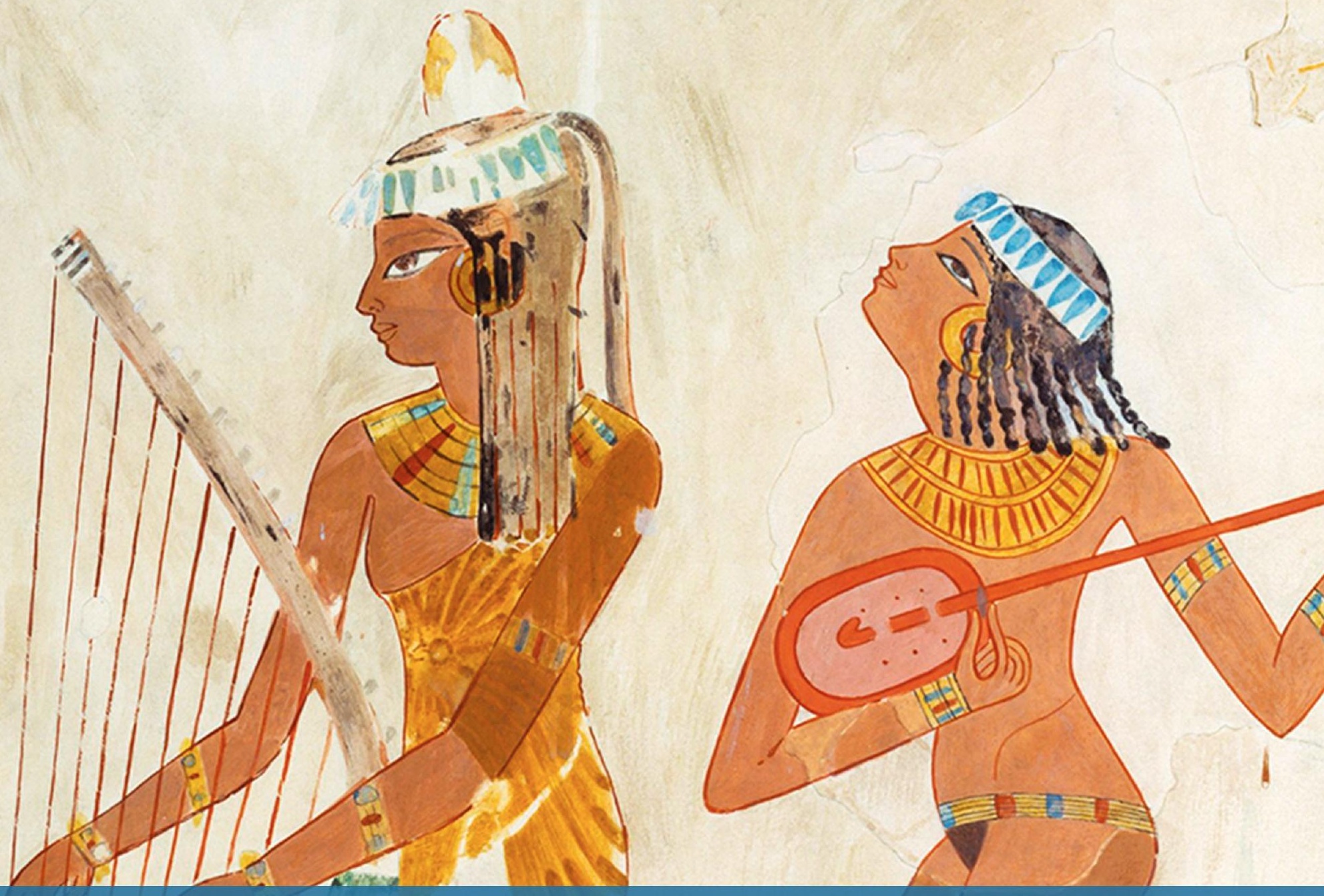

Revista digital de ciencia y Didáctica de la Historia

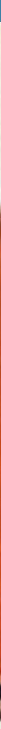




\section{Panta Rei \\ Revista Digital de Ciencia \\ y Didáctica de la Historia}

\section{9}

Revista anual

Fecha de inicio: 1995

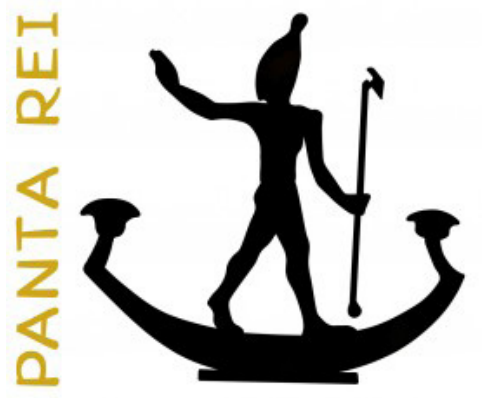

Revista Panta Rei. pantarei@um.es

Edita:

Centro de Estudios del Próximo Oriente y la

Antigüedad Tardía - CEPOAT

Edificio Universitario Saavedra Fajardo.

Universidad de Murcia

C/ Actor Isidoro Máiquez, 9

30007 - MURCIA - ESPAÑA

Teléfono: (+34) 868883890

cepoat@um.es

Web: www.um.es/cepoat/pantarei

Edición 2019

ISSNe: 2386-8864

Responsable de la presente edición: Consejo Editorial Panta Rei.

UNIVERSIDAD DE MURCIA centro de estudios del próximo oriente y la antigüedad tardía

En Portada: Fragmento de pintura de la tumba de Djeserkareseneb (TT38), Tebas. (fotografía del Metropolitan Museum).

Responsables de los textos: Sus autores.

ISSN: 1136-2464

Depósito legal: MU-966-1995 


\section{CONSEJO DE REDACCIÓN}

\section{Coordinador editorial}

Egea Vivancos, Alejandro

[Didáctica de las Ciencias Sociales, UMU]

\section{Editores}

Jiménez Vialás, Helena

[UMU]

López Muñoz, Dámaris

[UJA]

Meseguer Gil, Antonio José

[CEPOAT, UNED]

Sáez Giménez, David Omar

[CEPOAT, UMU]

Sánchez Mondéjar, Celso Miguel

[Patrimonio Inteligente]

\section{Secretaria}

Arias Ferrer, Laura

[Didáctica de las Ciencias Sociales, UMU]

\section{Responsable informático}

Martínez García, José Javier

[CEPOAT, UMU]

\section{Traducción y corrección lingüística}

Martínez Martínez, Cristina

[Sociedad Española de Lenguas Modernas]

Albaladejo Albaladejo, Sara

[ISEN, UMU]

\section{CONSEJO ASESOR}

Adroher Auroux, Andrés María [Arqueología, Universidad de Granada]

Albero Muñoz, M. ${ }^{a}$ del Mar [Historia del Arte, Universidad de Murcia]

Alia Miranda, Francisco [Historia Contemporánea, UCLM]

Arciniega García, Luis [Historia del Arte, Universidad de Valencia]

Barrio Barrio, Juan Antonio [Historia Medieval, Universidad de Alicante]

Castellano i Solé, Núria [Egiptología, Schola Didàctica Activa S.L.]
Chapman, Arthur [History Education, University College of London, Reino Unido]

Cid López, Rosa María [Historia Antigua, Universidad de Oviedo]

Cobacho López, Ángel [Derecho, Universidad de Murcia]

Cuenca López, José María [Didáctica de las Ciencias Sociales, Universidad de Huelva]

Egea Bruno, Pedro M. ${ }^{a}$ [Historia Contemporánea, Universidad de Murcia]

Feijoo Martínez, Santiago [Arqueología, Consorcio Ciudad Monumental de Mérida]

García Atienzar, Gabriel [Prehistoria, Universidad de Alicante]

Ginestí Rosell, Anna [Filología Clásica, Katholische Universität Eichstätt-Ingolstadt]

González Monfort, Neus [Didáctica de las Ciencias Sociales, Universidad Autónoma de Barcelona]

González Soutelo, Silvia [Arqueología, Universidad de Vigo]

Haber Uriarte, María [Prehistoria, Universidad de Murcia]

Hernández de la Fuente, David [Historia Antigua, Universidad Complutense]

Hutson, Scott R. [Anthropology, University of Kentucky, EE UU]

Igual Luis, David [Historia Medieval, UCLM]

Irigoyen López, Antonio [Historia Moderna, Universidad de Murcia]

Jover Maestre, Francisco Javier [Prehistoria, Universidad de Alicante]

Mahony, Simon [Digital Humanities, University College of London, Reino Unido]

Marsilla de Pascual, Francisco Reyes [Técnicas historiográficas, Universidad de Murcia]

Martínez-Burgos García, Palma [Historia del Arte, UCLM]

Mathis, Christian [Didaktik der Geschichte, PH Zürich]

Miralles Maldonado, José Carlos [Filología Clásica, Universidad de Murcia]

Molina Gómez, José Antonio [Historia Antigua, Universidad de Murcia]

Mónica Ghirardi [Historia Moderna, Universidad Nacional de Córdoba, Argentina]

Navarro Espinach, Germán [Historia Medieval, Universidad de Zaragoza]

Noguera Celdrán, José Miguel [Arqueología, Universidad de Murcia]

Ortiz Heras, Manuel [Historia Contemporánea, UCLM]

Panzram, Sabine [Historia Antigua, Universität Hamburg]

Pérez Molina, Miguel Emilio [Filología Clásica, Universidad de Murcia]

Prados Martínez, Fernando [Arqueología, Universidad de Alicante]

Sánchez Ibáñez, Raquel [Didáctica de las Ciencias Sociales, Universidad de Murcia]

Sancho Gómez, Miguel Pablo [Educación, UCAM]

Victoria Moreno, Diego [Historia Contemporánea, UNED]

Vilar García, María José [Historia Contemporánea, Universidad de Murcia]

Vivas Sainz, Inmaculada [Historia del Arte, UNED]

Zamora López, José Ángel [Próximo Oriente Antiguo, CCHS-CSIC] 



\section{Índice}

\section{Artículos}

La imagen de la Prehistoria en el cine y los géneros del cine prehistórico. Un mundo de hombres mono, bikinis y dinosaurios.

Alberto Lombo Montañés.

Trabajo y roles de género durante la Prehistoria. Un estudio sobre su percepción en el alumnado de Historia.

María Pastor Quiles y Daniel Mateo Corredor.

Memoria cultural en el Egipto Faraónico. Algunas reflexiones sobre su origen, función y pervivencia histórica.

Antonio Pérez Largacha.

La representación de la danza dentro de las escenas de banquete de las tumbas tebanas privadas de la XVIII dinastía egipcia.

Miriam Bueno Guardia.

La "Sala del Fresco" de Micenas. Revisión de las interpretaciones del programa iconográfico y nueva lectura en relación a los espacios.

Pelayo Huerta Segovia.

Las advertencias de Quilón y Solón sobre la tiranía de Pisístrato.

Unai Iriarte.

La Virgen de la Leche. Arquetipo de mujer y madre en la pintura del Renacimiento español.

Patricia Castiñeyra Fernández

Innovación didáctica en Historia: un estado de la cuestión en torno a cuatro ejes temáticos.

Diego Luna Delgado.

\section{Reseñas}

Foster, B. R. (2016), The Age of Agade. Inventing empire in ancient Mesopotamia, Londres y Nueva York: Routledge, 438 págs.

Juan Álvarez García.

Alviz Fernández, M. y Hernández de la Fuente, D. (Eds.) (2017). De ópos a limes: el concepto de frontera en el mundo antiguo y su recepción. Madrid: Escolar y Mayo editores. 256 págs.

Ethan Yepes de la Hoz.

Clares Clares, M ${ }^{\mathrm{a}}$ E. (2017). Música y noches de moda. Sociedades, cafés y salones domésticos de Murcia en el siglo XIX. Murcia: Universidad de Murcia, Servicio de Publicaciones. 474 págs.

Elena Micó Terol 195

Goñi Zabalegui, A. (2018). Género y sociedad en el Egipto romano. Una Mirada desde las cartas de mujeres. Oviedo: Ediciones de la Universidad de Oviedo. 360 págs.

Alejandra Izquierdo Perales. 199

Normas de publicación/Publishing rules 



\title{
La "Sala del Fresco" de Micenas. Revisión de las interpretaciones del programa iconográfico y nueva lectura en relación a los espacios
}

\author{
The 'Room 31' at Mycenae: Reviewing the Interpretations of the Iconographic \\ Program and Giving a New Reading in Relation to Spaces
}

Huerta Segovia, Pelayo ${ }^{1}$

Universidad Autónoma de Madrid

Recibido: 31/01/2019

Aceptado: 26/07/2019

Para citar este artículo: Huerta Segovia, P. (2019). La "Sala del Fresco" de Micenas. Revisión de las interpretaciones del programa iconográfico y nueva lectura en relación a los espacios. Panta Rei. Revista Digital de Ciencia y Didáctica de la Historia, 91-111.

ISSNe: 2386-8864

DOI: $10.6018 /$ pantarei/2019/05

\section{Resumen}

En el presente estudio se aborda el programa iconográfico de la "Sala del Fresco" de Micenas con el objetivo de entender el significado de las pinturas, el propósito por el cual fueron concebidas, así como su relación con la actividad ritual del lugar. Para ello, revisando las teorías existentes, se procederá al análisis y a la interpretación de cada una de las figuras y de los motivos decorativos. Por último, se atiende al contexto arqueológico de la estancia y del resto de espacios con el fin de establecer un posible vínculo con otras salas vecinas del "Centro cultual", cuya relación es clave para una nueva lectura de las pinturas.

\section{Palabras clave}

Historia del Arte, Arqueología, Religión, Ceremonias, Mitología.

\section{Abstract}

The present study addresses the iconographic program of the 'Room 31' at Mycenae with the aim of understanding the meaning of the paintings, the purpose for which they were created as well as their relationship with the ritual activity carried out in the place. To that end, while reviewing the existing theories, we will proceed to the analysis and interpretation of each figure and the decorative motifs. To conclude, we will keep in mind the archaeological context of the room and the rest of the spaces in order to determinate a possible link with other nearby rooms of the 'Cultual Center', whose relationship is essential to give a new interpretation of the paintings.

\section{Keywords}

Art History, Archaeology, Religion, Ceremonies, Mythology.

1 Para contactar con el autor: Pelayo Huerta Segovia. Universidad Autónoma de Madrid. pelayohs@gmail.com. 


\section{Introducción}

El más conocido entre los santuarios urbanos micénicos es el denominado "Centro cultual de Micenas". Ubicado sobre la pendiente oeste de la ciudadela, la cual se encuentra en el extremo nororiental de la península del Peloponeso, es uno de los espacios sacros más antiguos de la acrópolis micénica, cuya ocupación viene atestiguada con seguridad al menos desde el LH I hasta el LH IIIB2-C, siendo a mediados del LH IIIB, es decir, en torno a los años 1260-1240 a.C. según la cronología absoluta de Cline (2010, tabla 2.2), el periodo de mayor esplendor constructivo (Wardle, 2015) (Tabla 1). Este emplazamiento se había concebido como un gran lugar de culto dedicado a diferentes divinidades, si tenemos en cuenta que hay varias estructuras que pudieron haber tenido una función cultual: el Santuario Gamma, la "Casa del Fresco" (o 'Room 31'), y el "Templo". Otros de los edificios principales del enclave serían la "Casa Tsountas" y, por supuesto, el Megaron. Los tres anteriormente destacados serían, a priori, espacios de sacrificio o de celebración de rituales, a juzgar por la estructura y los espacios de los mismos, los altares y la presencia de una amplia cantidad de objetos votivos que evidencia que en el lugar habría actividades cultuales específicas (Cultraro, 2006).

Con el descubrimiento del "Templo" y de la "Sala del Fresco", por Taylour en 1968-1969, se bautizó el emplazamiento como "Centro cultual de Micenas". A partir de entonces se ha venido aceptando generalmente que esta área se constituyó como un complejo de estructuras controladas por el palacio (Chapin, 2016; Wardle, 2015).

Tabla 1

Cronología absoluta aproximada de la Edad del Bronce Egea.

\begin{tabular}{|c|c|c|c|c|c|}
\hline Crete & Dates BC & Cyclades & Dates BC & Mainland & Dates BC \\
\hline Early Minoan I & $3100-3000$ & $\mathrm{ECl}$ & $3100-3000$ & $\begin{array}{l}\text { Early Helladic } \\
\text { I }\end{array}$ & $3100+$ to 3000 \\
\hline (EMIB) & $(2900-2650)$ & $\begin{array}{l}\text { Kampos } \\
\text { Phase }\end{array}$ & $2900-2650$ & & \\
\hline EMIIA & $2650-2450 / 00$ & $\begin{array}{l}\text { ECII (keros- } \\
\text { Syros phase) }\end{array}$ & $2650-2500$ & EHII & $2650-2500$ \\
\hline EMIIB & $2450 / 00-2200$ & Kastri Phase & $2500-2250$ & $\begin{array}{l}\text { Later EHII/ } \\
\text { Lefkandi }\end{array}$ & $2500-2200$ \\
\hline EMIII & $\begin{array}{l}2200- \\
2100 / 2050\end{array}$ & $\begin{array}{l}\text { Kastri Phase } \\
\text { and into } \\
\text { Phylakopi I } \\
\text { Phase }\end{array}$ & $2400-2200$ & EHIII & $2250-2210 / 50$ \\
\hline $\begin{array}{l}\text { Middle Minoan } \\
\text { IA }\end{array}$ & $\begin{array}{l}2100 / 50- \\
1925 / 00\end{array}$ & $\begin{array}{l}\text { Middle } \\
\text { Cycladic- } \\
\text { Phylakopi I } \\
\text { Phase }\end{array}$ & $2200-$ & $\begin{array}{l}\text { Middle } \\
\text { Helladic }\end{array}$ & 2100/50- \\
\hline MMIB & $\begin{array}{l}1925 / 00- \\
1875 / 50\end{array}$ & & & & \\
\hline MMII & $\begin{array}{l}1875 / 50- \\
1750 / 00\end{array}$ & & & & \\
\hline MMIII (A-B) & $\begin{array}{l}1750 / 00- \\
1700 / 1675\end{array}$ & & & & \\
\hline $\begin{array}{l}\text { Late Minoan } \\
\text { IA }\end{array}$ & $\begin{array}{l}1700 / 1675- \\
1625 / 00\end{array}$ & Late Cycladic & $\begin{array}{l}1700 / 1675- \\
1625 / 00\end{array}$ & Late Helladic & $\begin{array}{l}1700 / 1675- \\
1635 / 00\end{array}$ \\
\hline
\end{tabular}




\begin{tabular}{|c|c|c|c|c|c|}
\hline LMIB & $\begin{array}{l}1625 / 00- \\
1470 / 60\end{array}$ & LCII & 1625/00- & LHIIA & $\begin{array}{l}1635 / 00- \\
1480 / 70\end{array}$ \\
\hline LMII & $\begin{array}{l}1470 / 60- \\
1420 / 10\end{array}$ & & & LHIIB & $\begin{array}{l}\text { 1480/70- } \\
1420 / 10\end{array}$ \\
\hline LMIIIA1 & $\begin{array}{l}1420 / 10- \\
1390 / 70\end{array}$ & LCIII & $1420 / 1400$ & LHIIIA1 & $\begin{array}{l}1420 / 1410- \\
1390 / 70\end{array}$ \\
\hline LMIIIA2 & $\begin{array}{l}\text { 1390/70- } \\
1330 / 15\end{array}$ & & & LHIIIA2 & $\begin{array}{l}\text { 1390/70- } \\
1330 / 15\end{array}$ \\
\hline LMIIIB & $\begin{array}{l}1330 / 15- \\
1200 / 1190\end{array}$ & & & LHIIIB & $\begin{array}{l}1330 / 1315- \\
1200 / 1190\end{array}$ \\
\hline LMIIIC & $\begin{array}{l}1200 / 1190- \\
1075 / 50\end{array}$ & & & LHIIIC & $\begin{array}{l}1200 / 1190- \\
1075-50\end{array}$ \\
\hline
\end{tabular}

Fuente: reelaboración propia de la "Tabla de Cronología Absoluta aproximada de la Edad del Bronce Egea" propuesta en Cline (2010, p. 23, tabla 2.2.).

No obstante, este es un aspecto que parecen dejar de lado algunos de los estudiosos que han tratado la "Sala del Fresco" y su programa iconográfico, un ejemplo excepcional de pintura mural del mundo micénico, de difícil interpretación, sobre todo por el estado fragmentario en el que se encuentra y por su singularidad. De este modo, en el presente trabajo se procederá a un pormenorizado análisis e interpretación del fresco de la sala, teniendo en cuenta la función de los distintos espacios que forman parte del complejo de la "Casa del Fresco" y las construcciones colindantes. Para la identificación de las figuras del fresco, se partirá principalmente de los estudios de Marinatos (1988), Rehak (1992) y Chapin (2016), los únicos que han tratado de manera específica este fresco, cuyas teorías servirán de base para algunas interpretaciones, siendo aceptadas en determinados casos, pero superadas en otros. Así, se intentará aportar algunas identificaciones y lecturas diferentes a las de los autores anteriores. Debido a que se estudia un ejemplo que no encuentra paralelos directos en la pintura mural micénica tanto desde el punto de vista compositivo como en el plano iconográfico, se verá necesario compararlo tanto con otros soportes como con las representaciones artísticas de otros territorios como Creta, o incluso de ámbito sirio y egipcio.

\section{El complejo de la "Sala del Fresco": espacios y depósito arqueológico}

El complejo de la "Sala del Fresco", datado del LH IIIB1 (Wardle, 2015), que comprende los años 1315/1300-1260/50 a.C., está formado por varias estancias alrededor de la sala principal, la designada como 'Room 31', aquella que tiene la pintura mural y que es el objeto de estudio de este artículo (Figura 1). La "Sala del Fresco", núcleo primigenio del complejo, estaba constituida por un hogar elaborado y columnas de madera a ambos lados, y originariamente se accedía a ella desde el patio central a través de un pasillo. En la esquina noroeste había una tarima con una estatuilla con lo que parece haber sido un pectoral decorado con cuentas de vidrio. En el suelo se encontraron gran número de objetos, fundamentalmente cerámica de diferentes tipos, y delante del altar un conjunto de nueve vasijas. Al lado, había una gran vasija de plomo sobre la que descansaba parte de un cartucho egipcio perteneciente al reinado de Amenhotep III (1391-1353 a.C.) (Chapin, 2016; French, 2004). Junto al altar, se hallaron objetos muy interesantes: un vaso de piedra cretense, la empuñadura de una espada, y una pieza en marfil en forma de león. Entre estas piezas, figuraba también la cabeza de marfil de una figura supuestamente masculina, que seguramente se había caído de la plataforma, la cual podría habría sido un objeto de culto en representación de una divinidad (French, 2004). 


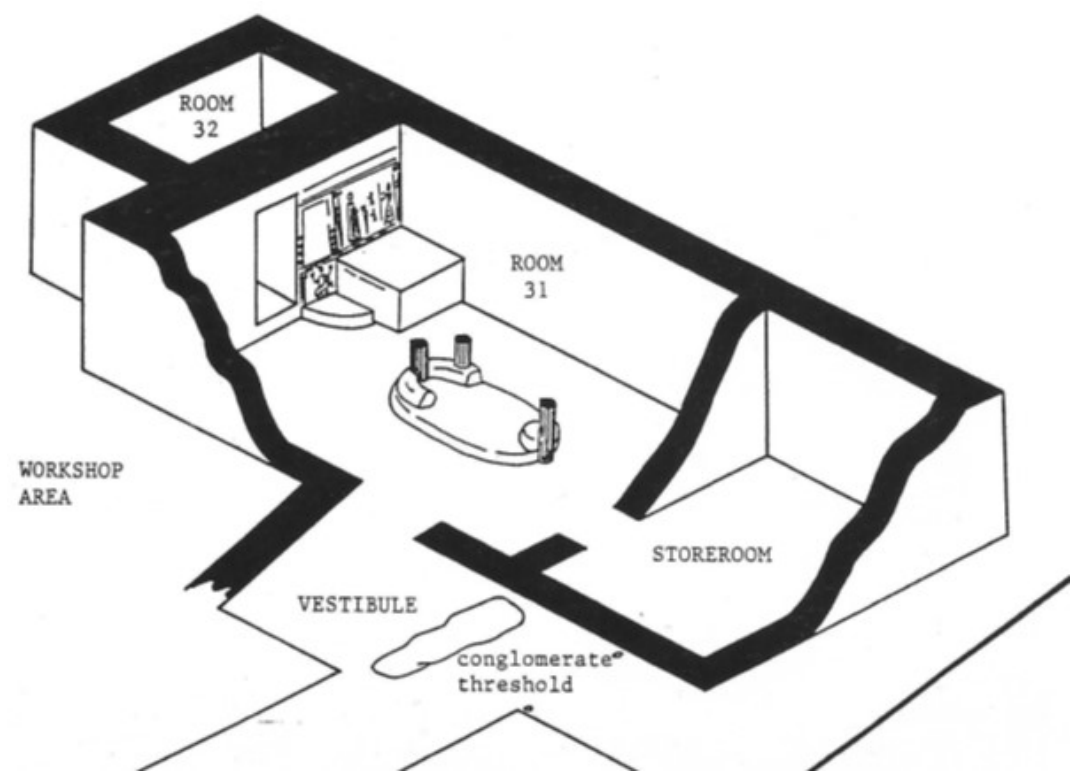

Figura 1: "Sala del Fresco" y salas adyacentes. Fuente: Rehak (1992, PI. IXa).

Al este, detrás de la estancia central, hay un pequeño espacio identificado como un sanctum interior, y conocido como la "Sala de los Marfiles" o 'Room 32'. Al oeste, se abre una sala que apenas ha proporcionado hallazgos, pero que por sus dimensiones pudo haber funcionado como una suerte de almacén. Al norte, está el área de la antesala y un acceso, que tampoco ofrecen información arqueológica relevante y que servirían de entrada a la estancia en la última fase de ampliación del complejo. (French, 2004; Morgan, 2005) El resto de salas se construyeron en un estadio ligeramente posterior, cuestión que retomará al final.

En base a todos estos hallazgos, la presencia sobretodo del altar y del hogar, la iconografía del panel y los diferentes espacios del complejo de la "Sala del Fresco", se piensa que la función de la sala llamada 'Room 31' era la de pequeño santuario, en la que se llevarían a cabo diferentes prácticas rituales relacionadas con la actividad de culto del enclave.

\section{Programa iconográfico e interpretaciones}

Una cuestión fundamental a la hora de entender esta sala, es la vinculación que existe entre el programa iconográfico que se representa sobre el altar y los demás espacios que forman parte del complejo de la "Sala del Fresco", siendo una parte imprescindible a la hora de analizar e interpretar el significado del panel (Figura 2). El uso del espacio y su relación con la pintura mural en el ámbito del Egeo del Bronce es determinante. Cain (1997, p. 7) hablando de las pinturas de la Edad del Bronce, pero haciendo referencia a los frescos de Thera, señala: "the ritual activity reflected here is likely to have had a functional relationship with the architectural space these paintings embellish". Estas ideas se pueden entender también en relación a las pinturas y al espacio de la "Sala del Fresco", cuestión desarrollada en profundidad más adelante. Del mismo modo, la relación entre los objetos aquí depositados con respecto la plataforma y el fresco es algo que hay que tener en cuenta.

En este sentido, la primera conexión que hay que tener presente es en relación al altar. La presencia de las plataformas o de este tipo de altares tan comunes en los santuarios egeos, se concibe como un indicador de la actividad cultual, el lugar donde se dispondrían las ofrendas, siendo el elemento protagonista de los rituales (Renfrew, 1985). Por tanto, el carácter visual y narrativo de la pintura reforzaría la función cultual de la estancia, sirviendo de fondo a los rituales que tendrían lugar en torno al altar. 


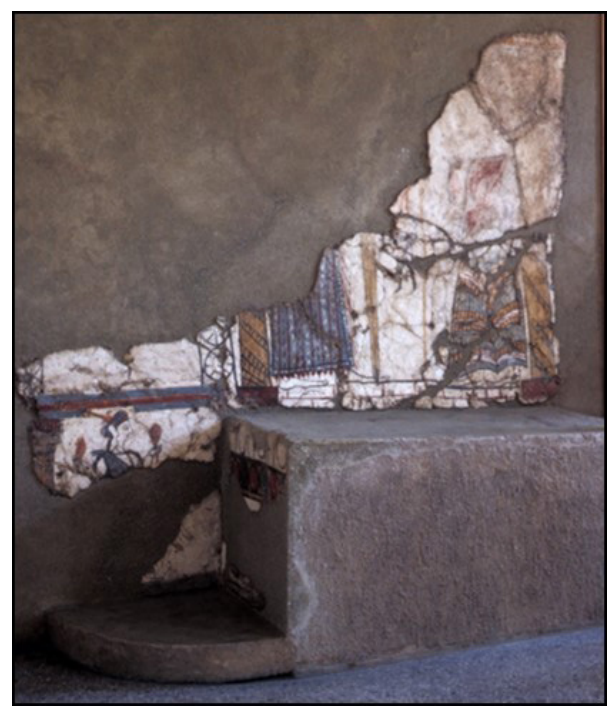

Figura 2: Estado actual del fresco, Museo Arqueológico de Micenas. Fuente: Dowden.

El fresco propiamente dicho se divide en dos registros adaptándose a la superficie del muro, funcionando el paralelepípedo como separador, cuyo lado menor también presenta motivos decorativos. En una primera aproximación, y en base a la reconstrucción aceptada generalmente (Marinatos, 1988) se distinguen claramente tres figuras femeninas protagonistas (Figura 3). En el plano superior, la mujer de la izquierda lleva un manto largo y se apoya en una especie de espada, mientras que la de la derecha lleva el vestido característico de influencia minoica y porta un bastón. Sendas figuras se encuentran en un espacio limitado por columnas y entre ambas se sitúan dos figurillas masculinas (una de color negro y otra de color rojo) hacia el centro del panel. En el plano inferior, la denominada "Figura femenina con grano", bautizada así por Rehak (1992), se sitúa delante de una columna del mismo tipo que las anteriores, sostiene espigas en la mano mientras avanza hacia la derecha y está acompañada por un animal o ser fantástico. En la mayor parte de reconstrucciones se aceptaba que lo que acompaña a esta figura es un grifo, sobre todo a partir de la interpretación de Marinatos (1988). No obstante, algunos estudios posteriores ofrecen otras interpretaciones, algo que se tendrá en consideración a lo largo del presente trabajo. Este es el caso de Rehak (1992) autor que lo identifica con un león.

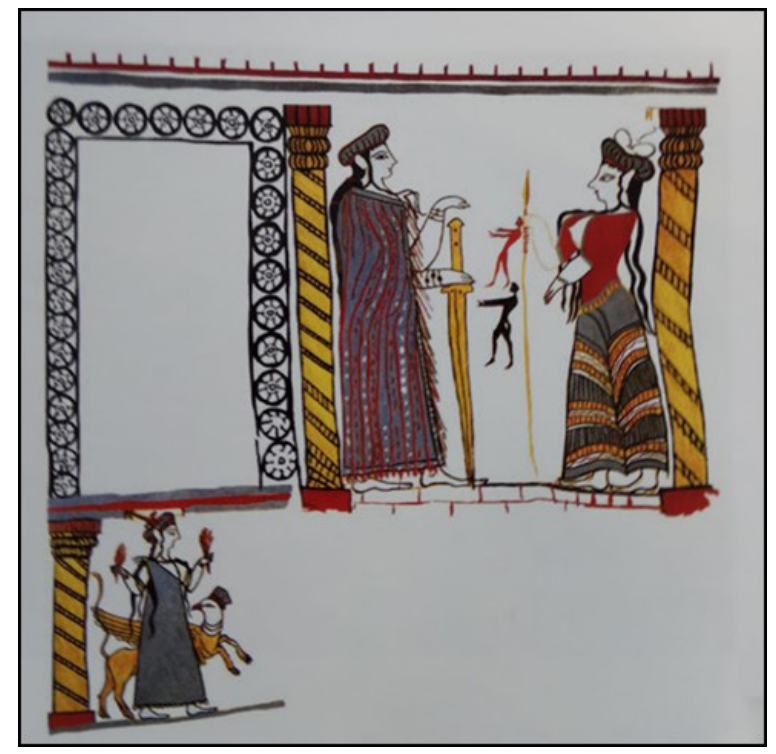

Figura 3: Reconstrucción del fresco propuesta por Marinatos (1988, p. 254). 
En cuanto la lectura del fresco hay diferentes interpretaciones, puesto que la conservación parcial de los paneles presenta un obstáculo a la hora de entender su significado en función a las figuras y a los objetos representados. Cultraro (2006) habla de unas figuras de naturaleza divina a juzgar por las posturas de los personajes y los atributos que los acompañan. El italiano entiende el programa iconográfico como una escena de investidura del poder, pues identifica las dos mujeres del registro superior como dos diosas que están por transmitir los insignia dignitatis al futuro soberano, el cual, según él, podría ser una de las figurillas del centro (Cultraro, 2006). El término insignia dignitatis se traduciría como atributos de poder, los cuales, para la sociedad micénica, representan el liderazgo y la materialización de dicho poder en manos de su soberano, el wanax (Gonzato, 2012). Sin embargo, y a pesar de que las dagas o las espadas pudieran funcionar como insignia dignitatis, no se comparte ni que la escena represente una investidura de poder, pues tanto en el arte minoico como en el micénico no existen ejemplos claros de representaciones del soberano (Maran-Stavrianopoulou, 2007; Rehak, 1995) (y de existir, el wanax difícilmente estaría representado con esa forma y a esa escala tan reducida) ni tampoco la identificación de todas las figuras como divinidades, como se argumentará a lo largo de los siguientes párrafos.

En nuestro estudio, a diferencia de la interpretación anterior, se pretende vincular más estrechamente el fresco al carácter cultual de la sala (y del complejo) y a los rituales que tendrían lugar alrededor del altar, con una intención narrativa. En este sentido, se puede adscribir a la primera de las tres funciones que, según Marinatos (1985), tienen los frescos del Egeo: la de narrar un ritual, aquel que se daría en la misma sala que la pintura. En cuanto a la segunda y a la tercera función, serían, respectivamente, perpetuar un ritual similar que tuviera lugar en el exterior, apelando a él al representarlo en un espacio interior, y servir de fondo a diferentes eventos que se dieran en el lugar (Marinatos). No obstante, el significado de las pinturas que se dan en esta sala, no se puede limitar a la primera de estas funciones. Por ello, se recoge a continuación otra triple clasificación que vino dada por Hägg (1985) en la que las funciones de las pinturas irían más vinculadas a la temática de estas: la primera sería la de perpetuar las escenas de culto o de rituales, la segunda responde a guiar y a dirigir los participantes del ritual, y la tercera, en el caso que se representen divinidades, invocar o "invitar" la presencia divina en la ceremonia que tiene lugar en el espacio. Como se tratará en último lugar, sugerimos que el fresco cumpliría tanto estos tres papeles como el señalado anteriormente, pues el mensaje que se pretende transmitir y la voluntad de aquellos que lo concibieron no respondería a una idea simple ni a un propósito en concreto; una posibilidad que, según Hägg (1985), sería susceptible de darse sólo en algunos casos particulares los cuales tienen que ser analizados con mayor profundidad. La "Sala del Fresco", que se constituye así como uno de estos casos, tiene un programa iconográfico que conlleva una gran complejidad, por lo que antes de proceder a la posible identificación de cada una de las figuras y a la hipótesis final, es fundamental entenderlas en el espacio ficticio que se representa en el fresco y en relación al resto de elementos pictóricos.

En primer lugar, la mayor parte de los elementos del programa iconográfico evidencian la herencia cultural y religiosa minoica de la cual bebe la sociedad micénica, una impronta que dejó una huella muy fuerte en el arte micénico (Blakolmer, 2013; Immerwahr, 1990); pues, tanto los motivos arquitectónicos como algunos atributos de los personajes, especialmente los ropajes (Jones, 2015), nos remiten al arte minoico. En el registro superior y a la izquierda de la escena principal se dispone una falsa puerta decorada con un marco con rosetas, motivo característico de la pintura mural minoica. Es una decoración que los micénicos recuperaron para algunas de las fachadas de las tumbas más importantes, como por ejemplo el caso de la "Tumba 53" de Micenas, que tiene una puerta con una decoración similar con rosetas, que puede verse como un precedente (Rehak, 1992). Este motivo con rosetas se plasmará posteriormente en soportes como sarcófagos, además de la pintura mural, y en forma de relieves (Chapin, 2016; Kontorli-Papadopoulou, 1987; Rehak, 1992). Lo interesante es que se situaba justo al lado de la puerta que daba la entrada a la estancia adyacente, la 'Room 32'. Sin embargo, originalmente, antes de que la "Sala de los Marfiles" fuera concebida, es muy posible que la "Sala del Fresco" estuviera conectada a través de un pasadizo 
con las estancias del templo, en especial con "la Sala de los Ídolos", aludiendo quizá a la transición entre estas (Morgan, 2005), cuestión a tratar en el último capítulo.

En el panel central, ambas figuras caminan sobre un nivel que parece estar pavimentado por un enlosado de mármol, algo que sería común en los palacios cretenses y micénicos, en las estancias más importantes. Las columnas que delimitan la escena principal pueden tener, del mismo modo, su precedente en la arquitectura minoica con esos pilares decrecientes que cumplían una función sustentante de las estancias y que más tarde se proyectarían en el Megaron micénico. No obstante, las columnas tuvieron una reelaboración y adaptación en el mundo micénico dando lugar a nuevas formas como las que vemos aquí, pues estas imitan a las columnas de factura elaborada que aparecen en otros frescos micénicos, con basa, capiteles y una espiral que recorre el fuste (Rehak, 1992).

Aquel motivo decorativo que no ofrece dudas de su origen minoico es el representado en la cara menor de la plataforma (Figura 4). Se representa una arquitectura con banda decorada con círculos, motivo pictórico frecuente en los edificios cretenses, y coronado por los "cuernos de la consagración", el conocido símbolo minoico que serviría de ornamento escultórico y pictórico no sólo en los santuarios y palacios (tanto en los muros interiores como en las fachadas), sino en otro tipo de soportes, como los altares o la glíptica (Marinatos, 1993). D’Agata (1992), quien dedica un estudio en profundidad al tema, señala que los cuernos de la consagración serían una invención de Cnoso desde donde se usaría el símbolo en concepto de "poder territorial que emana desde el centro". Una visión diferente sobre el origen y la adopción de los "cuernos de la consagración" en Creta la aporta Banou (2008), quien sugiere la posibilidad de asociar "los cuernos de la consagración" a la cosmología y a la religión del sol en Egipto, pudiendo ser, del mismo modo, un símbolo vinculado al sol en el mundo minoico. A modo de comparación con el fragmento del fresco aquí tratado, un ejemplo pictórico notable y cercano en cronología en el que se representan los "cuernos de la consagración" es la cara sur del sarcófago de Agia Triada, datado en el LM IIIA2, donde los símbolos estarían coronando un santuario que se dispone detrás de un altar (Alušík, 2005; Long, 1974; Rehak 1992) (Figura 5). Por tanto, en la "Sala del Fresco" la idea puede ser la misma que en el sarcófago, es decir, en ambos casos se estaría representando la fachada de un santuario.

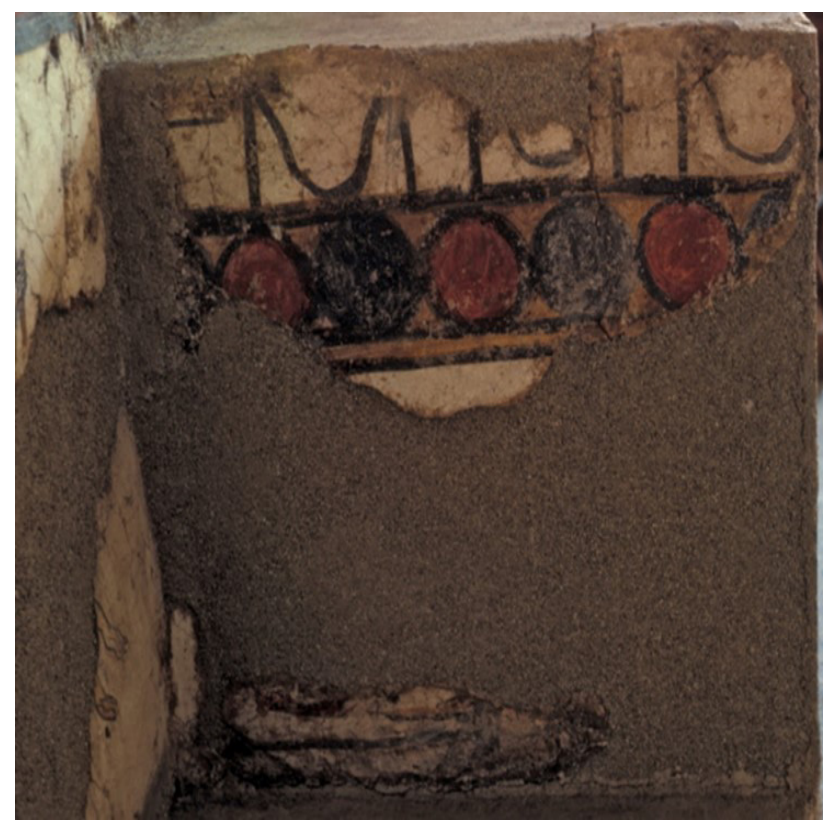

Figura 4: Cara menor del altar del fresco. Fuente: Dowden.

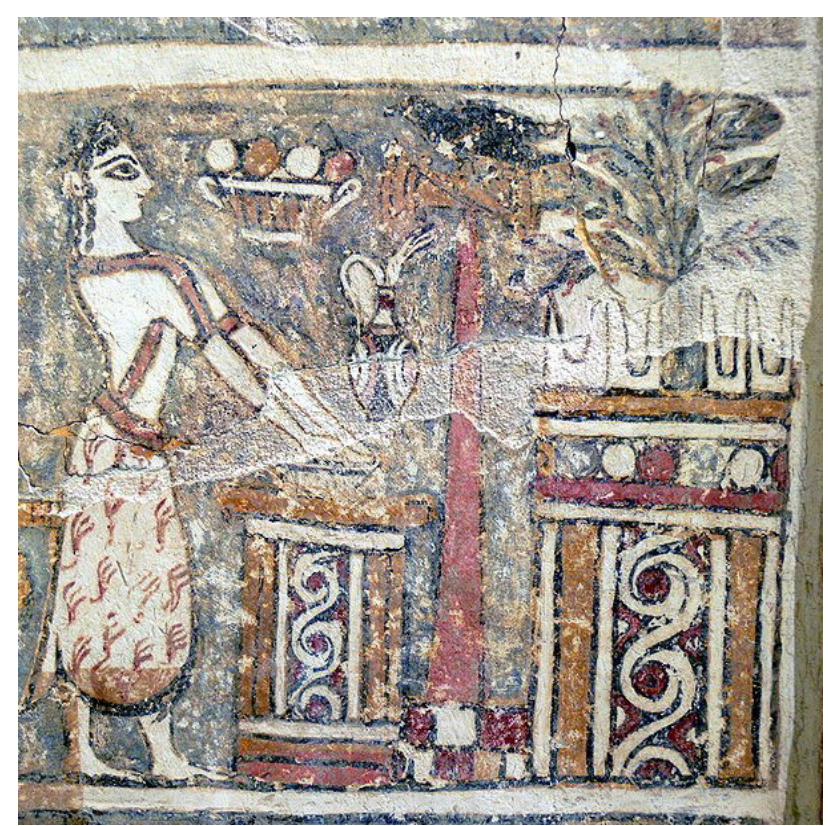

Figura 5: Fragmento del sarcófago de Agia Triada (cara sur), Museo Arqueológico de Heraclion. 
Teniendo en cuenta estos argumentos, las tres partes analizadas del programa iconográfico estarían representando tres espacios ficticios diferentes: una arquitectura exterior (la cara menor del altar), un espacio interior (el panel principal) y un espacio de transición (la falsa puerta). En cuanto al espacio representado en el panel menor ofrece una interpretación difícil. La presencia de una sola columna en lugar de dos es el principal obstáculo, pues podría hacer referencia a la integración de la "Figura femenina con grano" tanto en un espacio exterior como en un espacio interior. De este modo, podríamos hablar de cuatro espacios ficticios en total. De nuevo, queremos hacer hincapié en la importancia de la relación existente entre la pintura y los espacios, no sólo del complejo de la "Sala del Fresco", sino de los espacios ficticios que se pretenden crear en ella, como se acaba de evidenciar. Unos espacios ficticios cuya vinculación atiende tanto a la arquitectura minoica como a la micénica.

Una vez estudiado el marco en el que se inscriben las figuras, es hora de centrarnos en el análisis de las mismas. Al igual que los motivos decorativos vistos, que nos recuerdan a otros ejemplos minoicos, también podemos ver en las figuras paralelos más allá del mundo micénico. Cada una de las tres figuras femeninas está representada con unas vestimentas, gestos y atributos específicos a los que hay que poner atención puesto que son claves para entender su estatus e identidad dentro de la sociedad micénica (Chapin, 2016). En este sentido, la posición y los gestos de cada figura pueden aludir a la representación de una acción concreta que, a su vez, se integra en un mayor y complejo contexto que necesita ser entendido para poder identificar correctamente a cada personaje, como apunta la teoría de la "performatividad" (German, 2005). Este marco teórico, además, entiende que la edad pero sobre todo el género (en nuestro caso, femenino) de los personajes representados determina el acto que estos realizan y, por tanto, el modo en el que se interpretan las imágenes, puesto que el arte egeo enfatiza las características sexuales de las figuras y "asigna" diferentes papeles a los hombres y a las mujeres (German, 2005). Por ello, de ahora en adelante se analizarán las figuras de forma individual y estableciendo diferentes similitudes con otras representaciones con una iconografía similar para proceder a su identificación.

\subsection{Panel principal}

En primer lugar, es evidente que la escena principal es la del registro superior, de mayor tamaño, cuyos personajes llevan unos atributos y unos vestidos que subrayan el carácter sacro de la escena, como se comentó con anterioridad. De las dos figuras femeninas que aparecen, la de la izquierda parece ser el personaje más importante, tanto de esta escena como, en consecuencia, de la totalidad del fresco. La mujer lleva un pesado manto decorado con bandas azules y rojas, y con puntos en blanco, siendo un ropaje muy similar al que llevaría la figura conocida como "La Parisina" del Palacio de Cnoso (Figura 6), fechada en el LM II (Rehak, 1992). En cuanto a la espada que lleva, además de su evidente función como arma, era considerada un símbolo de poder (Chapin, 2016; Rehak, 1984; 1992).

Por tanto, a juzgar por el arma y el largo ropaje, atributos que serían pertenecientes a figuras de un alto estatus según Marinatos (1993), la figura femenina de la izquierda debe ser o bien una diosa, o bien alguien de una posición social muy alta, es decir, perteneciente a la élite micénica. Teniendo en cuenta que las dagas, como atributo de poder social y militar en la sociedad micénica, difícilmente estarían en manos de las mujeres al ser probablemente propiedad exclusiva del wanax y de la élite militar (Palaima, 1999) es más acertado inclinarse por la primera opción. De ser así, la espada indicaría la naturaleza y el carácter de la divinidad que la porta: una diosa guerrera. En este sentido, es significativo el hallazgo de la empuñadura de espada en la "Sala del Fresco" entre los objetos encontrados junto al altar (French, 2004), sugiriendo una posible función cultual de la espada en la ceremonia ritual que tendría lugar en la sala y su vinculación directa con la diosa guerrera. Así interpretan a esta figura autores como Blakolmer (2010) y Rehak (1984), siendo un motivo iconográfico presente tanto en las representaciones minoicas como en las micénicas. 


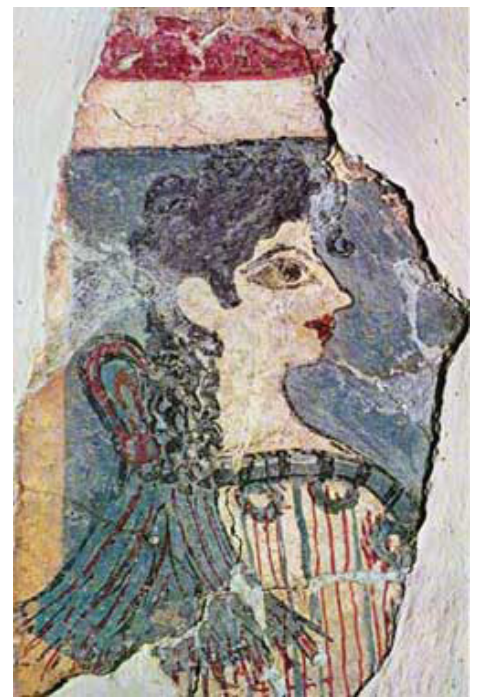

Figura 6: "La Parisina" o "Dama minoica" del palacio de Cnoso, Museo Arqueológico de Heraclion.

Fuente: odysseus.culture.gr.

A continuación, emergen entre ambas mujeres, las dos figurillas masculinas roja y negra, que habían sido interpretados como espíritus o genios (daimones) por Marinatos (1988). Por su parte, Rehak (1984), compara estas figurillas con los hombres representados en las escenas micénicas de procesión, portadores de ofrendas (concretamente los representados en la pintura mural del vestíbulo del palacio de Pilo, datado en el LH IIIB) (Figura 7), considerando que la diminuta escala de estas figuras, más que a genios o a epifanías de divinidades o espíritus, a lo que pretende aludir es a su menor estatus en relación con las otras figuras. Por ello sugiere que, nuevamente, en una asimilación por parte de los micénicos del arte minoico, estos hombrecillos simbolizarían los devotos de los dioses, que, curiosamente, están representados en el fresco como exvotos propiamente dichos. En cuanto a la diferencia de color, habla de la pretensión por distinguir a la población negra del Egeo de aquella blanca, individualizando a aquellos que pertenecerían al ámbito cercano al palacio cretense respecto al continente donde vivirían los nativos africanos (Rehak, 1992). Es decir, habría una voluntad en simbolizar que todos los sectores de la población son devotos de la diosa, sin excepciones.

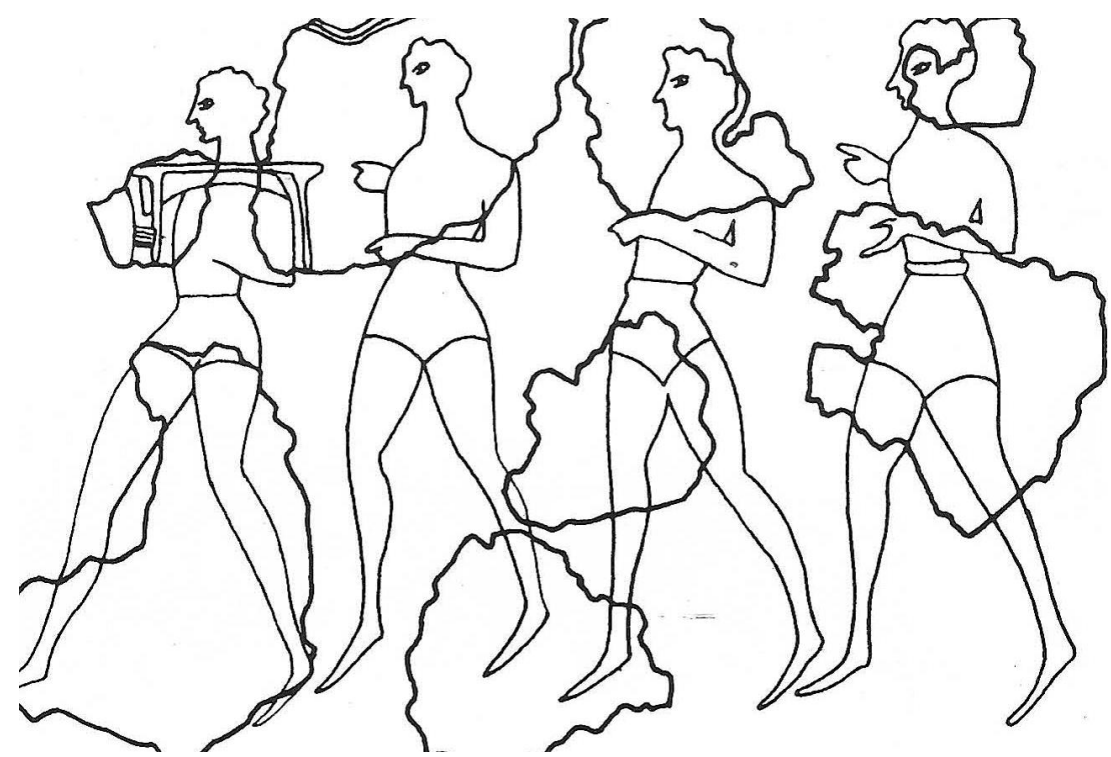

Figura 7: "Hombrecillos" procedentes del vestíbulo del palacio de Pilos. Fuente: Rehak (1992, PI. XIVb). 
En cuanto a la mujer de la derecha, portaría una especie de bastón o un cetro, nuevamente atributo perteneciente a la élite, comúnmente hallado en las tumbas micénicas y asociado al wanax en las tablillas en Lineal B (Palaima, 1995). A pesar de llevar un ornamental vestido de tradición minoica, varios frescos micénicos representan a las mujeres que participan en las procesiones con este ropaje (Rehak, 1992). No obstante, la posición y actitud de su cuerpo son diferentes respecto a las representaciones del mundo micénico, por lo que, de nuevo, Rehak (1992) la compara con una iconografía minoica: la de la potnia therôn o "diosa de los animales" flanqueada por leones que encontramos en un sello minoico (CMS II, 8, $\mathrm{n}^{\circ} 256$ ) (Figura 8). Sin embargo, a este sello que usa el autor le falta un elemento importante presente en el fresco, que podría funcionar como el elemento indicador de la naturaleza de esta figura femenina: las figurillas.

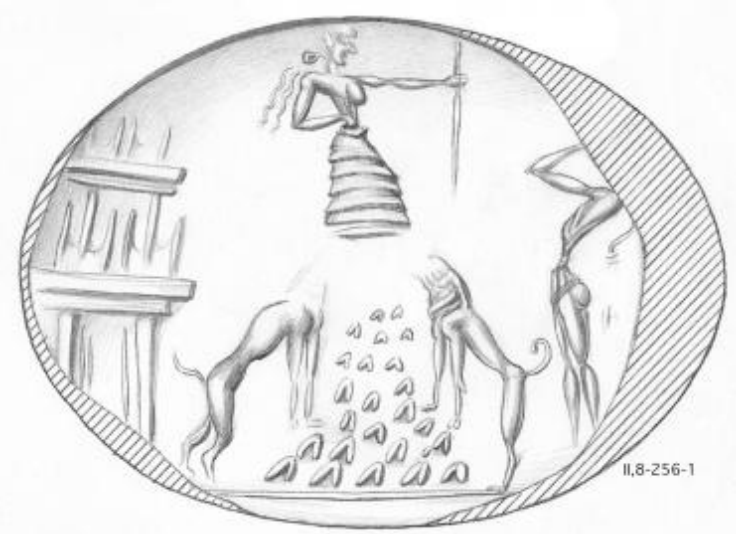

Figura 8: Sello minoico con la potnia therôn, Museo Arqueológico de Heraclion. Fuente: CMS II, 8, nº 256.

Teniendo en cuenta la anterior identificación con hombrecillos exvotos, la dirección que las figurillas siguen y la cercanía con el bastón de la mujer de la derecha, consideramos que estas se constituyen como una ofrenda de la mujer a la diosa. Por ello, esta figura femenina no sería tanto una diosa, como acepta el autor, sino una mujer oferente perteneciente a la élite o una sacerdotisa, al ser portadora de un cetro (Palaima, 1995), y al estar representada además en un menor tamaño que la diosa, aludiendo quizás a ese estatus y a su condición humana, siendo su vestimenta la misma que la de las mujeres que participan en procesiones y llevan ofrendas que se ven en los frescos micénicos, como ya había sugerido el mismo Rehak (1992). Sirva como comparativa la siguiente figura procedente de un fresco del Megaron de Micenas (Figura 9), fechado en el LH IIIA2, que podría ser similar a la mujer de la "Sala del Fresco" (Rehak, 1992). No obstante, es preciso señalar que es una reconstrucción hecha a partir de dos fragmentos, por lo que no hay que descartar otras alternativas.

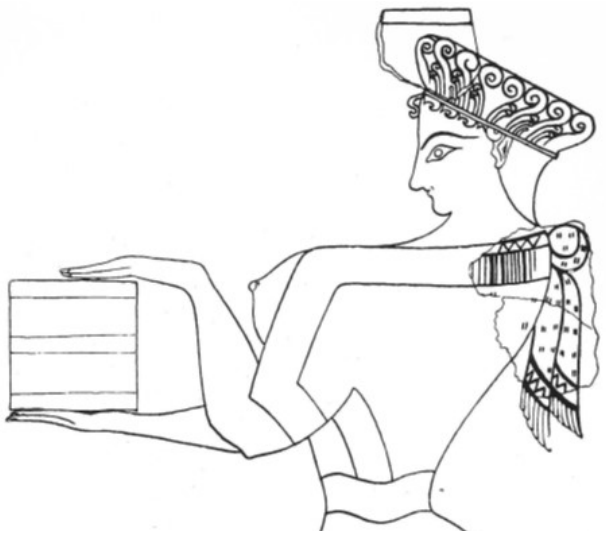

Figura 9: "Dama oferente” del megarón de Micenas. Fuente: Rehak (1992, PI. XVla). 


\section{2. "Figura femenina con grano"}

Es la figura cuyo espacio compositivo es el menor, pero al mismo tiempo aquella cuya interpretación suscita mayor debate dentro de la comunidad científica, erigiéndose la pieza clave para la lectura de este programa iconográfico. Los investigadores no se ponen de acuerdo en si es humana o divina, si estaba sentada o de pie y si guarda relación con el espacio que representa el panel principal y las figuras de mayor tamaño, o más bien con la arquitectura exterior que se representa en el lado menor del paralelepípedo (Chapin, 2016; Marinatos, 1988; Rehak, 1992). Además, el hecho de que esté sobre ese escalón curvilíneo que forma parte de la plataforma misma, sugiere su relación directa con el altar y la arquitectura que representa, por lo que adquiere más importancia (Rehak, 1992) (Figura 10).

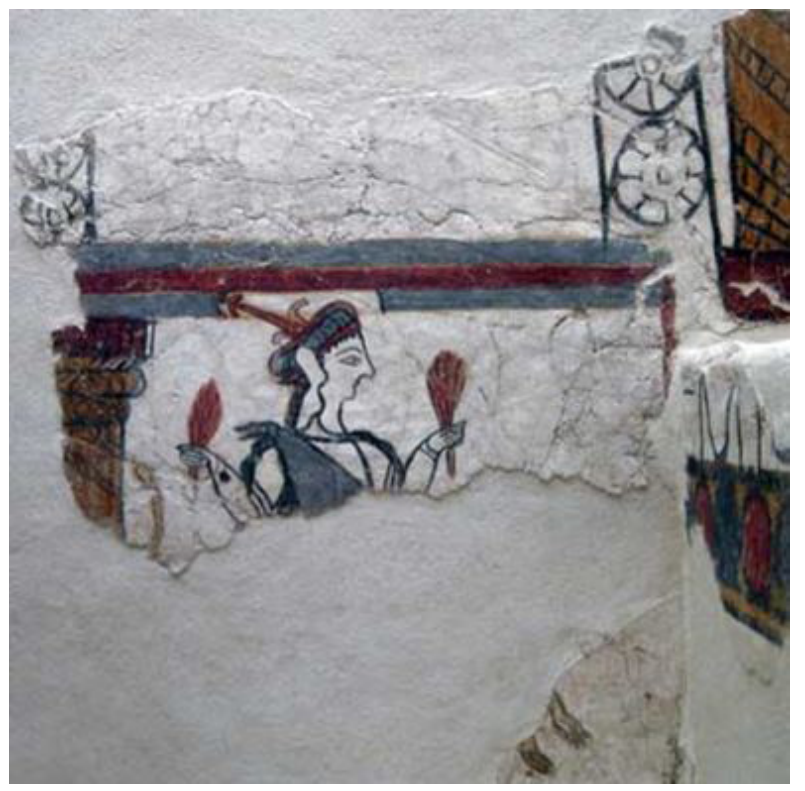

Figura 10: "Figura femenina con grano", Museo Arqueológico de Micenas. Fotografía de Almare, 2006. Fuente: Wikimedia Commons.

Taylour (1983) la había identificado primero como una sacerdotisa real que estaría ofreciendo frutos de la tierra a la diosa, pero, una vez que se descubrieron los restos pictóricos del animal, rectifica en un estudio posterior que se trata de una diosa menor acompañada de una criatura híbrida con pezuñas de cabra y cola de león (Chapin, 2016). Por su parte, Chadwick (1976) la entendió con una Potnia, principal diosa del panteón micénico, la cual sería para Boëlle (2001) la divinidad protectora de la soberanía y estaría presente siempre en los textos en tanto que receptora de ofrendas, cuyo término (po-ti-ni-ja) puede traducirse como "soberana" o "señora", el cual puede dar lugar a otros nombres en su yuxtaposición con otros términos, haciendo referencia o bien a diversas divinidades o bien a varios epítetos de la misma diosa (Varias, 2014). Mientras, Immerwahr (1990) la identificó con una diosa de la fertilidad por las espigas que lleva en la mano. La de Marinatos (1988) es una de las interpretaciones más aceptadas generalmente y que dio lugar a la reconstrucción que se incluye en este trabajo (Figura 3), tanto por la identificación del ser o animal, como por la de la figura femenina, la cual la autora concibe como una sacerdotisa. Sin embargo, Rehak (1992) no apoya las identificaciones de Marinatos y habla de esta figura como una diosa, al igual que los investigadores anteriores. De nuevo, Marinatos y Rehak presentan interpretaciones diferentes, en relación tanto a la figura como a aquello que lo acompaña. No obstante, a día de hoy, siguen constituyéndose como los dos autores que ofrecen un estudio más completo sobre el fresco y esta figura en particular.

Si bien se podría ver cierto paralelo de la "Figura femenina con grano" con las figurillas gesticulantes de las escenas de sacrificio de la glíptica minoica o con las figurillas exvotos que 
se encuentran delante de los altares que representaban "la diosa de las serpientes", al tener una posición de los brazos similar (Marinatos, 1993), lo cierto es que nuestra figura tiene una actitud más hierática, y lo que sostiene en sus manos es grano de espigas, algo que no encontramos en el arte micénico ni minoico, convirtiéndolo en un motivo iconográfico excepcional. Por ello, con el fin de poder compararlo con algún motivo similar, Rehak (1992) lo relaciona con la iconografía de objetos procedentes de otras zonas del Egeo como el fragmento de píxide de marfil encontrado en Minet elBeida (Siria) del 1250 a.C. (Figura 11). En dicha pieza se representa una figura femenina sentada en una especie de altar, que remite a los de las colinas minoicas, y extiende sus manos para coger dos espigas, estando flanqueada por dos cabras. Al ser interpretada como una "diosa de los animales", el autor ve su paralelo en la potnia therôn minoica (Rehak, 1992). No es raro encontrar huellas de la iconografía y el arte minoico en ámbito sirio-palestino, pues hallazgos más antiguos como el de los frescos de Tel Kabri, datados en el siglo XVII a.C. y realizados en un estilo minoico, han llevado a algunos autores como los Niemeier (1998; 2000) y Cline, Yasur-Landau y Goshen (2011) a hablar de la presencia de artistas cretenses en territorio sirio. Esta presencia de artistas minoicos sería una de las consecuencias de ese fenómeno de intercambio de bienes y de interacción cultural entre élites que se produce entre Creta y algunos territorios de Oriente próximo e incluso Egipto y el cual, según Niemeier (1998; 2000), se daría entre los años 1650-1500 a.C. A pesar de ello, la composición y los atributos de la figura del fresco, así como su ropaje, son notablemente diferentes a los de la figura siria, por lo que para la interpretación de esta figura, como se tratará en profundidad posteriormente, nos alejamos de esta comparación e identificación de Rehak (1992).

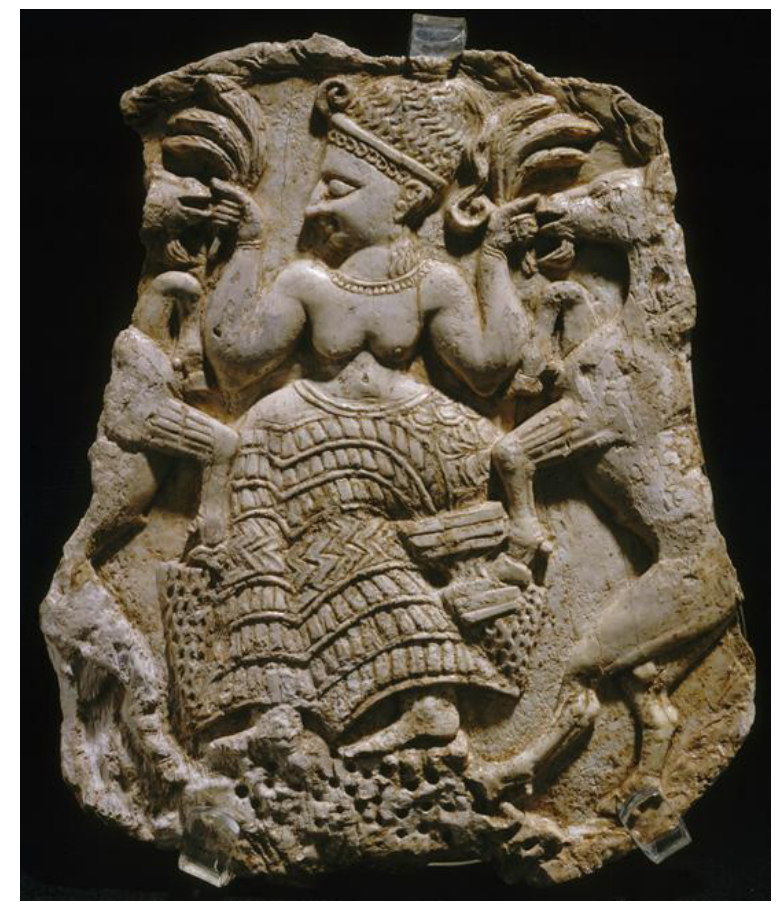

Figura 11: "Diosa alimentando cabras", fragmento de píxide en marfil, Minet el-Beida. Fuente: Museo del Louvre@ .

En cuanto al animal o ser fantástico que le acompañaría, como se mencionó con anterioridad, también suscita debate. Marinatos había planteado la posibilidad que fuera un león o un grifo, decantándose por este último, pues es dicho animal fantástico el que aparece con mayor frecuencia en frescos de Creta, Pilo, Thera y Keos. Así, la autora la interpreta como una sacerdotisa acompañada de un grifo (Marinatos, 1988). No obstante, todos estos grifos están pintados en color blanco, y el fragmento conservado hace ver una cola y unas garras de tonalidades amarillas. De este modo, Rehak (1992) toma el color de los leones y de los grifos representados en la pintura mural micénica 
como elemento diferenciador, entendiendo que el blanco era propio de los grifos y el amarillo de los leones, siendo una convención fija para la pintura. De entre los ejemplos que cita, destaca la "Sala del Trono" del Megaron de Pilo datada del LH IIIB, donde se representan en un mismo panel leones amarillos y grifos blancos (Rehak, 1992). Estos últimos, a su vez, son puestos en relación con los grifos blancos de la "Sala del Trono" de Cnoso por autores como Maran-Stavrianopoulou (2007), cuestión que les lleva a hablar de un ritual de epifanía divina en el que una sacerdotisa, actuando como la diosa en persona, ocuparía el trono en una ceremonia dirigida por el wanax. No obstante, no sólo encontramos ejemplos de grifos blancos en Creta, las Cícladas o en Grecia continental, cabe destacar uno de los fragmentos de los frescos de Tel Kabri encontrados en 2009, en los que se aprecia parte de las alas de un grifo blanco (Cline, Yasur-Landau y Goshen, 2011), así como varios restos pictóricos blancos de un grifo en el denominado "Fresco de la Caza" de Tell el Dab'a (identificada con Avaris, capital de los Hyksos) analizados en profundidad por Morgan (2010) y de una discutida cronología que comprende el LM IA-LM IB (Bietak, 2005; Manning, 1999). Ambos frescos están realizados en un claro estilo egeo y su creación se entiende dentro de ese período de intercambio cultural, material e ideológico entre élites del que hablábamos anteriormente (Morgan, 2010; Niemeier-Niemeier, 1998 y 2010). Precisamente, en el "Fresco de la Caza" aparecen también numerosos fragmentos en un color amarillo-anaranjado relativos a las figuras de unos diez leones, los cuales han sido individuados y estudiados recientemente por la misma Marinatos (2010), pudiendo ser así, paradójicamente, usados como argumento en contra de su identificación en tanto que grifo de 1988 (Marinatos) (Figura 12).

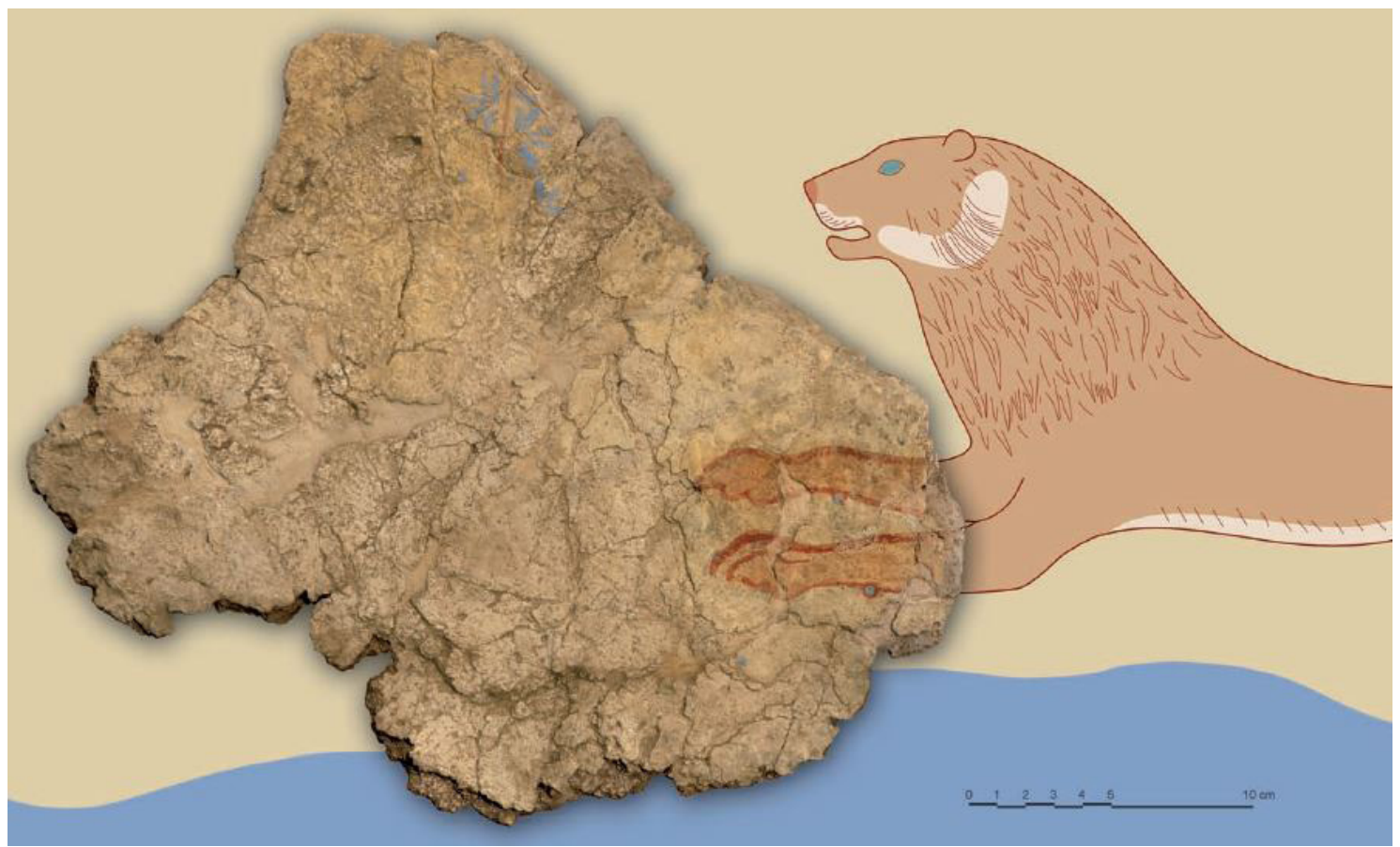

Figura 12: León n. 7 (F97), procedente del "Fresco de la Caza" de Tell el Dab'a. Fuente: Marinatos (2010, p. 339, Figura 20).

En base a estos ejemplos y debido a que en el fresco que nos ocupa los restos pictóricos del animal son amarillos, seguimos la identificación de Rehak (1992) quien sugiere que lo que acompaña a la figura femenina es un león, a pesar de que aparezca con mucha menor frecuencia que el grifo en los frescos micénicos. Si tenemos en cuenta los leones del palacio de Pilo o el relieve de la "Puerta de los Leones" de Micenas, el león simbolizaría el poder y prestigio asociados al palacio (Shaw, 1986). No obstante, también encontramos leones asociados a figuras femeninas que han sido interpretadas como divinidades en la glíptica tanto cretense como micénica, argumento 
de más peso para el autor. Por lo tanto, según Rehak (1992), la "Figura femenina con grano" sería una diosa que estaría acompañada por un león, como propone en su reconstrucción (Figura 13). Por otra parte, recordemos que entre los objetos de culto encontrados cerca de la plataforma había una estatuilla en eboraria con la forma de un león (French, 2004) sugiriendo, al igual que la empuñadura de espada, su uso cultual en los rituales de esta sala y su posible vinculación con las figuras representadas en el fresco.

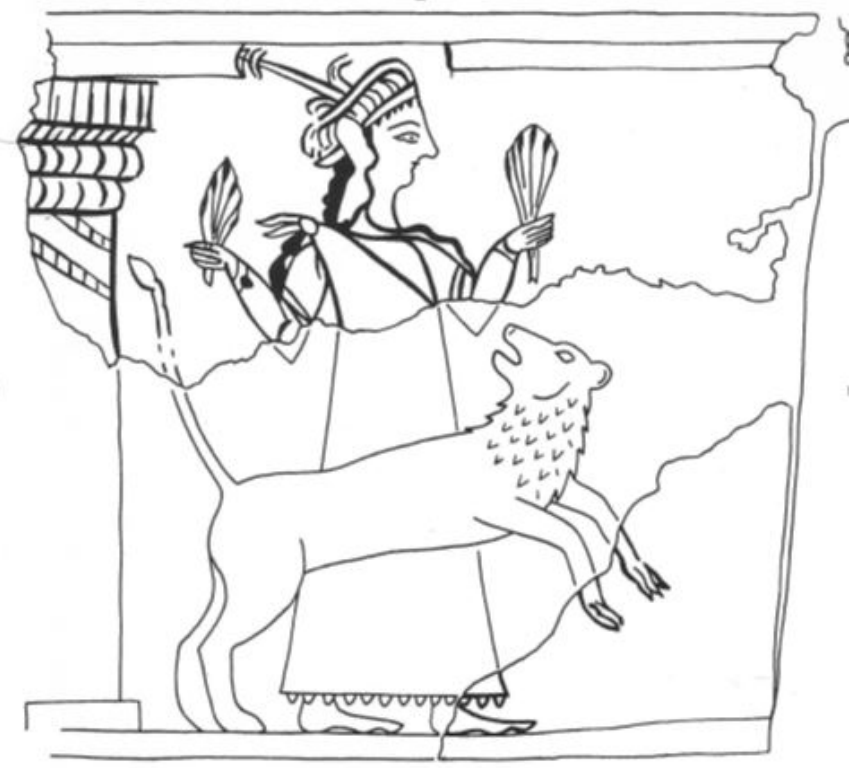

Figura 13: Reconstrucción del panel de la "Figura femenina con grano" propuesta por Rehak (1992, PI. XVIIIa).

La interpretación propuesta en este artículo está a medio camino entre la de Marinatos (por la figura) y la de Rehak (por el animal), siendo la misma que sigue Chapin (2016) quien señala que la figura femenina representa una sacerdotisa de alto rango acompañada de un león. Una identificación a la cual, por otra parte, se había acercado Taylour (1983) en su primera hipótesis, antes de que se hubieran descubierto los restos pictóricos del animal. Chapin basa su hipótesis en la vestimenta y joyas que lleva la mujer: un gorro plumado, un largo vestido que deja al descubierto un hombro y el brazalete con sellos pétreos. En relación a este último objeto, Younger (1977), había argumentado que los sellos colocados sobre pulseras o brazaletes, reconocibles tanto en la pintura mural como en las estatuillas votivas, estarían vinculados al alto estatus social al indicar la participación de su portador en asuntos burocráticos y, al mismo tiempo, podría vincularse a la conexión con la divinidad y a la protección que esta le brinda. De este modo, los argumentos de Younger (1977) apoyan esta identificación de la figura como una sacerdotisa de alto estatus, la cual estaría llevando ofrendas a la divinidad en términos de protección y favor divinos. Por otro lado, el manto que lleva en un hombro tiene sus paralelos en otras figuras de sacerdotisas del arte egeo, y concretamente en el fresco conocido como la "Joven Sacerdotisa" de la "Casa del Oeste" (Figura 14), bautizada como tal por la misma Marinatos (1985) y fechada entre el MM III-LM IA. Por ello, Marinatos (1988) había identificado nuestra figura del mismo modo, además de por su posición y su clara actitud oferente (Chapin, 2016). El gorro con plumas ya había sido comparado por Rehak (1992) con otros ejemplos minoicos en una iconografía relativa a sacerdotisas o a mujeres portantes de ofrendas en las procesiones, pero al asociar el león con un atributo divino, acabó identificándola como una diosa. Por su parte, para Chapin (2016) el león estaría vinculado a la identidad de la élite al ser un atributo de poder, de autoridad real y sagrada para muchas culturas del Egeo o del Mediterráneo oriental además de la micénica, como por ejemplo la egipcia. Sumando esto a lo argumentado anteriormente, Chapin (2016) afirma que la figura femenina no es sólo una sacerdotisa, 
sino una sacerdotisa que es miembro de la élite. Hasta aquí se comparten las ideas de esta autora, ${ }^{2}$ entendiendo la sacerdotisa y el león vinculados a ese componente regio y como símbolo de poder asociado al palacio micénico.

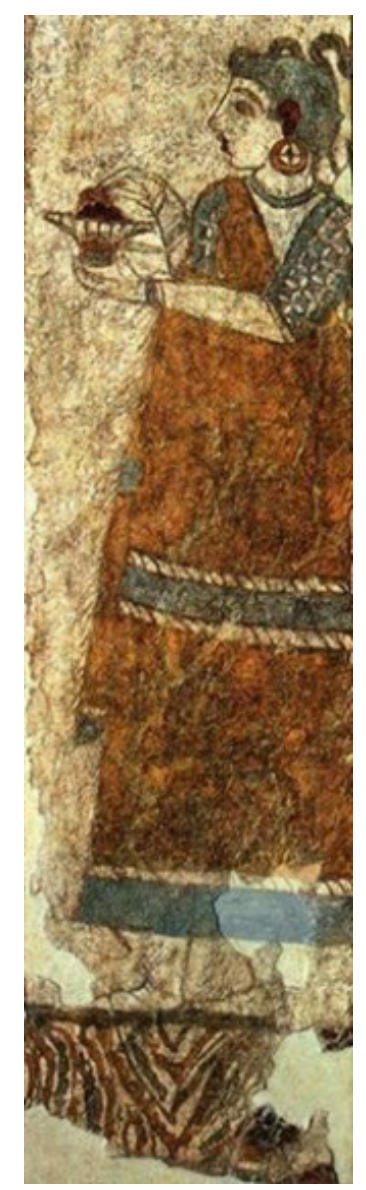

Figura 14: "Joven Sacerdotisa" ubicada entre la 'Room 4' y la 'Room 5' de la "Casa del Oeste" de Akrotiri, Museo Arqueológico de Atenas. Fuente: ancienthistoryfrescoesmaxndean.weebly.com.

No obstante, Chapin (2016) continúa vinculando no sólo la iconografía, sino la composición de estas pinturas con algunos ejemplos del arte egipcio, por la jerarquización del tamaño de las figuras y la división en varios registros, hablando de la adopción de una "Egyptinanising compositional formula" por parte de los artistas micénicos. A pesar de la influencia y el posible origen egipcios de ciertas iconografías del arte egeo (Vivas, 2013), no vemos necesario, en esta ocasión, buscar paralelos directos en Egipto para apoyar la identificación de esta figura como una sacerdotisa de alto estatus social, pues al igual que en las páginas anteriores, se pueden ver composiciones similares en la iconografía minoica.

En este sentido, el panel menor del fresco parece guardar un paralelo más estrecho con composiciones como la del sarcófago de Agia Triada (Figura 5). Proponemos así, que al igual que en esta escena del sarcófago, la sacerdotisa se está dirigiendo con las ofrendas en la mano hacia el santuario que viene representando en la cara menor del altar, en una clara intención narrativa y de continuidad compositiva que existiría entre ambas partes del programa iconográfico. El altar, al ser la parte más importante de toda actividad cultual y ritual (Renfrew, 1985), representa la esencia del santuario mismo. De este modo, en términos literarios, en la iconografía de estos paneles se

2 En cuanto a esta figura se refiere, pues Chapin (2016) había identificado la mujer de la derecha del panel principal con una diosa, interpretación que no se comparte en este estudio. 
daría una sinécdoque, en la que el altar es la parte y el santuario ficticio el todo. Este altar vendría entendido como el santuario en miniatura, el cual estaría vinculado probablemente a un culto de la divinidad del registro superior. Según lo anterior, nuestro estudio sugiere que la ofrenda de la "Figura femenina con grano" sería el colofón, la última parte del ritual que tendría lugar en los espacios del complejo, en la que una sacerdotisa se acercaría a ofrendar sobre el altar, acto acompañado de algunas otras prácticas. Unos rituales vinculados al fresco y a los espacios ficticios que en él se representan, el cual, como se repitió a lo largo del estudio, es necesario entender, así mismo, en relación a los espacios del complejo y de los edificios colindantes.

\section{Relación de la "Sala del Fresco" con el "Templo"}

En su estudio, Rehak (1992) había identificado la figura femenina con una diosa concreta, Sitopotnia (si-to-po-ti-ni-ja, "señora del grano") una divinidad agrícola que aparece junto a los trabajadores en una de las tablillas encontradas en el área de la "Ciudadela" pertenecientes a la serie Oi (701), estrechamente vinculada al "Centro cultual" (Varias, 2014). Por ello, el autor habla de un santuario donde se celebraría un culto por parte de trabajadores del ámbito palacial, es decir, una actividad cultual que estaría controlado por el wanax (Rehak, 1992). A pesar de que en el presente trabajo se identifique a la mujer con el grano como una sacerdotisa y no como una diosa, no se difiere de esta interpretación de Rehak (1992) de la función de la "Sala del Fresco" como un santuario vinculado a la estructura palacial. De hecho, como se argumentó anteriormente, la figura sería una sacerdotisa perteneciente a la élite. No obstante, en este artículo no se analizan las tablillas, sino que el argumento de peso reside en la vinculación del espacio de la "Sala del Fresco" con el complejo del "Templo", área también denominada como "Casa de los Ídolos". 3

Según Wardle (2015), la construcción tanto del complejo del "Templo" como de la 'Room 31' se dio en algún momento del LH IIIBI, aplicándose a esta última la pintura mural en un estado ligeramente posterior. Así, la "Sala del Fresco", en la primera fase de su construcción, conectaría directamente a través de un pasadizo con las salas del "Templo". El fresco se dispone al lado de una puerta, que originariamente daría paso a dicho pasadizo (Figura 15). En cuanto a la 'Room 32' o "Sala de los Marfiles" que comparte pared con el fresco actualmente, se crearía, algo más tarde, en lo que el autor denomina LH IIIBI Medio, obstaculizando la unión entre dichos complejos, quizá, como sugiere Wardle (2015), para separar el culto y diferenciar las prácticas rituales. Anteriormente a ambos complejos, el de la "Sala del Fresco" y el del "Templo", en el LH IIIB1 Antiguo se había levantado el Megaron, que compartiría pared más tarde con este último (Wardle, 2015). La proximidad con la estructura palacial sería, por tanto, un elemento determinante para el control que esta llevaría a cabo sobre los respectivos espacios. El uso de estos edificios cesaría a finales del LH IIIBI, cuando el incendio que afectó a la ciudadela de Micenas redujo a escombros ambos complejos, hacia el 1250 a.C. (Morgan, 2005).

También Morgan (2005) hace hincapié en la importancia de ese pasadizo o pasillo y sugiere incluso la relación directa de la "Sala de los Ídolos" con la "Sala de Fresco" por la similitud de los objetos y ofrendas que han sido encontradas en ambos espacios. Una cuestión que le hace, a su vez, entender el "Centro cultual de Micenas" como un complejo en el que se da un interconexión de los diferentes repertorios iconográficos con una multiplicidad de significados dependiendo de la ubicación de la imagen en estos espacios (Morgan, 2005). En esta línea, Albers (2004) también otorga especial importancia a los objetos y figurillas rituales encontrados las salas de ambos complejos,

3 Dependiendo de la bibliografía consultada, las denominaciones varían ligeramente, siendo necesarias algunas aclaraciones de la nomenclatura de estos espacios. El complejo del "Templo" y "Casa de los Ídolos" hacen referencia al mismo conjunto de estancias. Esta última denominación deriva de la estancia más al norte del complejo, la "Sala de los Ídolos"; mientras que la primera, hace referencia a la sala principal del mismo, la "Sala de las Plataformas", bautizada como el "Templo" debido al hallazgo de objetos y de un registro arqueológico que indican la actividad cultual que existiría en el lugar y en el resto de espacios. 
los cuales Wardle (2015) vincula al patronazgo de la élite. En este sentido, el mismo Rehak (1992) había hecho énfasis en el hecho de que tanto los atributos (la espada, el cetro, el león, el brazalete) como los motivos arquitectónicos del fresco están vinculados a una iconografía de élite, como se explicó a lo largo de nuestro artículo. Por lo que esta relación de los testimonios hallados en ambas salas con la élite, nos permite pensar en una relación estrecha entre las estancias del "Templo" y las del área de la "Sala del Fresco", entendiéndolas como espacios controlados bajo el ámbito palacial, cuestión clave para determinar la naturaleza y el mensaje que pretende transmitir las pinturas, y poder articular así una nueva hipótesis.

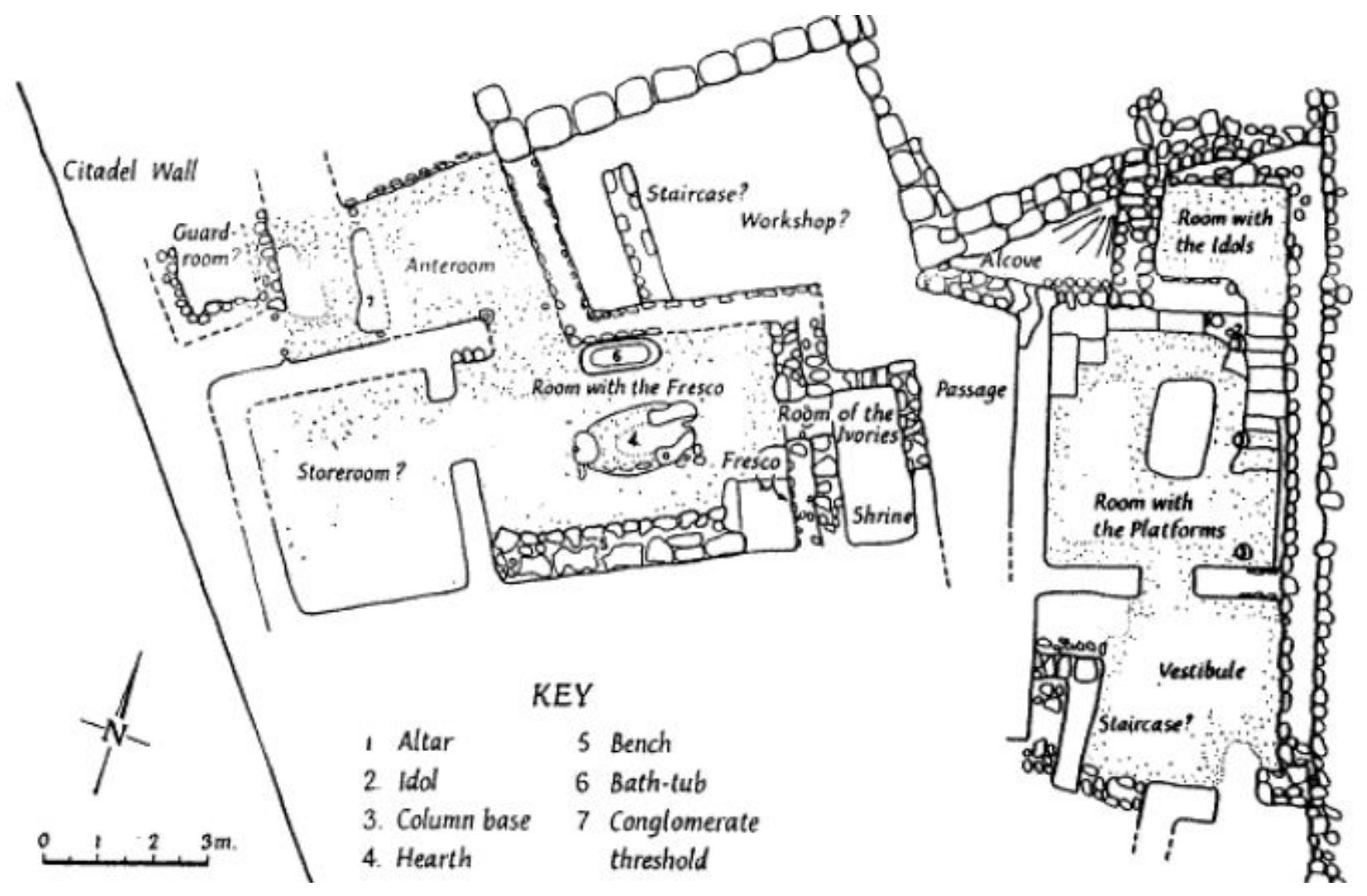

Figura 15: Complejos de la "Sala del Fresco" y del “Templo". Fuente: Morgan (2005, p. 163).

\section{Reflexiones finales}

A lo largo del presente estudio se ha hecho hincapié en la importancia de entender todo el contexto arqueológico, desde el depósito arqueológico y los objetos hallados en las salas, hasta la función de las salas mismas. Pues, las pinturas aquí analizadas se caracterizan por su excepcionalidad, al ser concebidas con una mayor complejidad que otras representaciones pictóricas del mundo micénico. Por ello, para su correcta interpretación era necesario entender la función de los diferentes espacios.

Además, para la articulación de las diferentes teorías que se fueron aportando sobre la identificación iconográfica, algunas diferentes a las ya existentes, se ha tenido en cuenta otro aspecto fundamental de la pintura mural que parece que el resto de investigadores han dejado en un segundo plano: la función narrativa. En las primeras páginas se trató en profundidad los diferentes papeles que podía tener la pintura minoica y micénica, comentando así que este programa iconográfico no podía adscribirse a una de las funciones en concreto, así como la importancia de entender la representación individualizada de cada figura femenina en el marco de la "teoría de 
la performatividad". No obstante, de todas ellas, la función narrativa es aquella más evidente y es fundamental para comprender el significado del fresco en conjunto, a partir de la cual se pueden entender el resto de funciones.

En este sentido, la hipótesis propuesta en este artículo se entiende ante todo bajo los conceptos de continuidad compositiva y narrativa que se darían a través de los paneles y de las diferentes figuras, cuya identificación en conjunto no recoge ninguna investigación anterior: una diosa guerrera frente a una mujer perteneciente a la élite o sacerdotisa que le hace ofrendas, $y$, por último, una sacerdotisa acompañada de un león y vinculada, del mismo modo, al ámbito palacial. Con ello, la nueva lectura se basa en que la sacerdotisa del panel menor, dirigiendo sus espigas de grano al altar, funcionaría como el último elemento de este programa iconográfico, como la figura protagonista, la cual estaría narrando un ritual real que tendría lugar en estos espacios. En una cultura como la micénica en la que la gran mayor parte de la población es iletrada, el arte mural no sólo sirve para embellecer y definir unos espacios ni es concebido tan sólo para la simple representación de una iconografía religiosa, sino que se erige como una útil herramienta en la que las imágenes tienen el poder de transmitir unas ideas y de integrar a los espectadores en el contexto (cultual, en nuestro caso) de dichos espacios. De este modo, el fresco de la 'Room 31' se constituye como un ejemplo excepcional de pintura mural que, entre otras funciones, opera como instrumento de narración visual y de comprensión del ritual para los participantes.

A su vez, la actividad cultual y ritual aquí celebrada formaría parte de los mismos ritos desempeñados en las salas del complejo del "Templo", con las que, como se comentó, estuvo unida en alguna fase de su construcción. Un complejo de estancias cuyo culto vendría organizado y controlado desde el cercano palacio, con el cual estaría estrechamente vinculado el programa iconográfico de la "Sala del Fresco".

En definitiva, sugerimos que la 'Room 31' sería el escenario principal para el desarrollo de dicha actividad cultual, funcionando su altar, probablemente, como el lugar donde se daría el clímax y se pondría fin a las prácticas rituales encabezadas por la sacerdotisa y en honor de la divinidad guerrera del registro superior, a la cual se invoca a través de su representación como receptora de ofrendas. Además, recordemos que el marco arquitectónico decorativo en el que se integra la figura con el grano no es de fácil identificación, pudiendo tratarse tanto de un espacio exterior como de un espacio interior; o bien uno de transición, como la falsa puerta que se sitúa justo encima de la sacerdotisa, aludiendo quizás a ese itinerario ritual que esta debía seguir y que, a través del pasadizo, conectaba todas estas salas. Por lo que, además de narrar el ritual, el fresco también estaría dirigiendo a la sacerdotisa hacia el punto clave del complejo, perpetuando estos ritos iniciados en otro espacio y continuados en esta estancia, sirviendo las pinturas, a su vez, de fondo y de marco conceptual de la celebración ritual.

\section{Abreviaturas}

CMS II, 8. Gill, A.V., Müller, W., Pini, I. y Platon, N. Corpus der Minoischen und Mykenischen Siegel: Iraklion, Archäologisches Museum. Teil 8. Die Siegelabdrücke von Knossos unter Einbeziehung von Funden aus anderen Museen. Mainz. 2002.

\section{Bibliografía}

Albers, G. (2004). Re-evaluating Mycenean sanctuaries. En M. Wedde (ed.) Celebrations: sanctuaries and the vestiges of cult activity. Papers from the Norwegian Institute at Athens (pp. 111-149). Bergen: Astrom Editions.

Alušík, T. (2005). Architecture in the Aghia Triada Sarcophagus - Problems and Possible Solutions. Eirene. Studia Graeca et Latina, 4, 26-45.

Banou, E. (2008). Minoan 'Horns of Consecration' revisited: a symbol of sun worship in palatial and post-palatial Crete? Mediterranean Archaeology and Archaeometry, 8(1), 27-47. 
Bietak, M. (2005). The setting of the Minoan wall paintings at Avaris. En L. Morgan (ed.), Aegean Wall Painting: A Tribute to Mark Cameron (pp. 83-90). London: The British School at Athens.

Blakolmer, F. (2010). A pantheon without atributes? Goddesses and gods in Minoan and Mycenean iconography. En J. Mylonopoulous (ed.), Divine Images and Human Imaginations in Ancient Greece and Rome (pp. 21-61). Leiden \& Boston: Brill.

Blakolmer, F. (2013). Was there a "Mycenaean Art"? Or: Tradition without Innovation? Some Examples of Relief Art. En J. Wellhartne y F. Ruppenstein (eds.), Tradition and Innovation in the Mycenaean Palatial Polities. Proceedings of an International Symposium held at Aegean and Anatolia Department (Vienna, 2013) (pp. 87-112). Vienna: Mykenische Studien, 34.

Boëlle, C. (2001). Po-ti-ni-ja: unité ou pluralité? En R. Laffineur y R. Hägg (eds.), Potnia. Deities and Religion in the Aegean Bronze Age. Proceedings of the 8th International Aegean Conference (Göteborg University, 2000) (pp. 403-409). Liège: Université de Liège - Austin: University of Texas at Austin.

Cain, C. D. (1997). The Question of Narrative in Aegean Bronze Age Art. Toronto: National Library of Canada.

Chadwick, J. (1976). The Mycenaean World. Cambridge: Cambridge University Press.

Chapin, A. (2016). The Performative Body and Social Identity in the Room of the Fresco at Mycenae. En M. Mina, S. Triantaphyllou y Y. Papadatos (eds.), An Archaeology of Prehistoric Bodies and Embodied Identities in the Eastern Mediterranean (pp. 81-97). Oxford: Oxbow Books.

Cline, E. (2010). The Oxford Handbook of the Aegean Bronze Age. Oxford: Oxford Handbooks.

Cline, E. H., Yasur-Landau, A. y Goshen, N. (2011). New Fragments of Aegean-Style Painted Plaster from Tel Kabri, Israel. American Journal of Archaeology, 115(2), 245-261.

Cultraro, M. (2006). I Micenei. Archeologia, storia, società dei Greci prima di Omero. Roma: Carocci editore.

D'Agata, A. L. (1992). Late Minoan Crete and Horns of Consecration: a symbol in action. En R. Laffineur y J. L. Crowley (eds.), Eikwn Aegean Bronze Age Iconography Shaping a Methodology. Proceedings of the 4th International Aegean Conference (University of Tasmania, 1992) (pp. 247-256). Liège, Université de Liège: Aegaeum.

French, E. B. (2004). Micenas. Capital de Agamenón. Barcelona: Bellaterra.

German, S. C. (2005). Performance, Power and the Art of the Aegean Bronze Age. Oxford: Archaeopress-BAR International Series.

Gonzato, F. (2012). Ostentazione di rango e manifestazione del potere agli albori della società micenea. Monza: Polimetrica.

Hägg, R. (1985). Pictorial programmes in the Minoan palaces and villas?. Bulletin de correspondance hellénique, 11, 209-217. Recuperado de https://www.persee.fr/doc/bch 0304$2456 \quad 1985$ sup $11 \quad 15280$.

Immerwahr, S. (1990). Aegean painting in the Bronze Age. London: Pennsylvania State University Press.

Jones, B. (2015). Ariadne's Threads: The Construction and Significance of Clothes in the Aegean Bronze Age. Leuven: Peeters Publishers.

Kontorli-Papadopoulou, L. (1987). Some Aspects Concerning Local Peculiarities of the Mycenaean Chamber Tombs. En R. Laffineur (ed.), Thanatos. Les coutumes funéraires en Egée à l'âge du Bronze. Actes du Colloque de Liège (1986) (pp. 145-160). Liège, Université de Liège: Aegaeum.

Long, C. R. (1974). The Ayia Triada Sarcophagus. A Study of Late Minoan and Mycenean Funerary Practices and Beliefs. Göteborg: P. Åström.

Manning, S. W. (1999). A Test of Time: The Volcano of Thera and the chronology and history of the Aegean and east Mediterranean in the mid second millennium BC. Oxford: Oxbow Books.

Maran, J. y Stavrianopoulou, E. (2007). Пóтvıo 'Avńp - Reflections on the Ideology of Mycenean Kingship". En E. Alram-Stern y G. Nightingale (eds.), Keimelion: Elitenbildung und Elitärer Konsum von derMykenischen Palastzeit bis zurhomerischen Epoche. Akten des Internationalen 
Kongresses vom 3. bis 5. (Salzburg, 2005) (pp. 285-298). Wien: Owan.

Marinatos, N. (1985). The Function and Interpretation of the Theran Frescoes. Bulletin de correspondance hellénique, 11, 219-230. Recuperado de https://www.persee.fr/doc/bch 030424561985 sup 1115281.

Marinatos, N. (1988). The fresco from Room 31 at Mycenae: problems of methods and interpretation. En E. French y K. Wardle (eds.), Problems in Greek Prehistory: papers presented at the centenary conference of the British School of Archaeology at Athens (Manchester, 1986) (pp. 245-254). Bristol: Bristol Classical Press.

Marinatos, N. (1993). Minoan Religion: Ritual, Image and Symbol. Columbia: University of South Carolina Press.

Marinatos, N. (2010). Lions from Tell el-Dab'a. Egypt and Levant, 10, 325-355.

Morgan, L. (2005). The Cult Centre at Mycenae and the duality of life and death. En L. Morgan (ed.), Aegean Wall Painting: A Tribute to Mark Cameron (pp. 159-171). London: The British School at Athens.

Morgan, L. (2010). An Aegean Griffin in Egypt: The Hunt Frieze at Tell el-Dab'a. Egypt and Levant, 10, 303-323.

Niemeier, B. y Niemeier, W. D. (1998). Minoan frescos in the Eastern Mediterranean. Aegean and the Orient, 69-98.

Niemeier, B. y Niemeier, W. D. (2000). Aegean Frescoes in Syria-Palestine: Alalakh and Tel Kabri. En S. Sherratt (ed.), The Wall Paintings of Thera. Proceedings of the First International Symposium, 2 (Athens, 1997) (pp. 763-802). Athens.

Palaima, T. G. (1995). The Nature of Mycenaean Wanax: Non-indoeuropean Origins and Priestly Functions. En P. Rehak (ed.), The Role of the Ruler in the Prehistoric Aegean. Proceedings of a Panel Discussion presented at the Annual Meeting of the Archaeological Institute of America (New Orleans, 1992) (pp. 119-143). Liège: Université de Liège - Austin: University of Texas at Austin-Aegaeum.

Palaima, T. G. (1999). Mycenaean militarism from a textual perspective. Onomastics in context: lāwos, dāmos, klewos. En R. Laffineur (ed.), Actes de la 7e Rencontre égéenne internationale (Université de Liège, 1998) (pp. 366-379). Liège: Université de Liège-Aegaeum.

Rehak, P. (1984). New observations on the Mycenean 'Warrior Goddess', Archäologischer Anzeiger, 4, 535-545.

Rehak, P. (1992). Tradition and Innovation in the Fresco from Room 31 in the 'Cult Center' at Mycenae. En R. Laffineur y J. L. Crowley (eds.), Eikwn. Aegean Bronze Age Iconography Shaping a Methodology. Proceedings of the 4th International Aegean Conference (University of Tasmania, 1992) (pp. 39-74). Liège: Université de Liège- Aegaeum.

Rehak, P. (1995). Enthroned Figures in Aegean Art and the Function of the Mycenaean Megaron. En P. Rehak (ed.), The Role of the Ruler in the Prehistoric Aegean. Proceedings of a Panel Discussion presented at the Annual Meeting of the Archaeological Institute of America (New Orleans, 1992) (pp. 95-118). Liège: Université de Liège-Aegaeum.

Renfrew, A. C. (1985). Towards a Framework for the Archaeology of Cult Practice. En C. Renfrew et al. (eds.), The Archaeology of Cult: The santuary of Phylakopi. British School at Athens Studies. Supplementary Volumes (pp. 11-26). London: Thames and Hudson.

Shaw, M. (1986). The Lion Gate Relief at Mycenae Reconsidered. Festschrift for Prof. G. Mylonas. Archaeological Society of Athens, 108-123.

Taylour, W. (1983). The Mycenaeans. Ancient Peoples and Places (Revised edition). London: Thames and Hudson.

Varias, C. (2014). Po-ti-ni-ja y si-to-po-ti-ni-ja en las inscripciones en Lineal B de Micenas. En A. Bernabé y E. R. Luján (eds.), Donum Mycenologicum. Mycenaean Studies in Honour of Francisco Aura Jorro (pp. 189-199). Peeters: Louvain - Walpole.

Vivas, I. (2013). Egipto y el Egeo a comienzos de la XVIII Dinastía: Una visión de sus relaciones, antecedentes y su influencia iconográfica. Oxford: Archaeopress-BAR International Series. 
Wardle, K. (2015). Rephrasing the past: where was the "Cult Centre" at Mycenae? En A. L. Schallin y I. Tournavitou (eds.), Proceedings of the conference Mycenaean Up to Date: The Archaeology of the Northeastern Peloponnese - Current Concepts and New Directions (Swedish Institute at Athens, 2010) (pp. 577-596). Estocolmo: Swedish Institutes at Athens and Rome.

Younger, J. (1977). Non-sphragistic uses of Minoan-Mycenaean sealstones and rings. Kadmos, 16, 141-159. 



\section{Panta Rei}

PANTA REI es una revista digital de investigación orientada a la Historia y otras ciencias afines. Su principal objetivo es la transmisión del conocimiento científico, dando una oportunidad también a los jóvenes investigadores que quieren abrirse camino en el estudio de las ciencias humanas y sociales. Se compone de estudios originales relacionados con la disciplina histórica así como su didáctica y difusión. Las diferentes secciones que componen la revista son: artículos de investigación, entrevistas a profesionales, recensiones de monografías de actualidad y crónicas de congresos o eventos científicos relevantes.

Todos los artículos publicados son objeto de un proceso de revisión a cargo de un mínimo de dos evaluadores, que se consideran expertos en el ámbito temático del artículo propuesto. Nuestro deseo es poder ofrecer unos contenidos rigurosos, de calidad y de interés.

EI CEPOAT (Centro de Estudios del Próximo Oriente y la Antigüedad Tardía de la Universidad de Murcia) es la institución encargada de la coordinación y gestión de la revista, desde donde anualmente se lanzará la convocatoria para aquellos que estén interesados en publicar sus trabajos, siempre relacionados con la Historia, Arqueología, Historia del Arte, Didáctica de la Historia, etc.

PANTA REI is a digital journal focused on History and other sciences related to it. Its main objective is the transmission of scientific knowledge by giving also an opportunity to young researchers who want to make their way in the study of human and social sciences. It is composed by original studies related to History, as well as its didactics and promotion. The different sections of this journal are: research articles, interviews to professionals, recensions on monographs about current issues and reports about congresses or relevant scientific events.

All the articles published are subject to a revision process carried out by a minimum of two reviewers who are considered to be experts in the field of the article proposed. Our wish is to offer rigorous contents with quality and being of interest to the reader.

CEPOAT (Centre of Studies of the Middle East and Late Antiquity of the University of Murcia) is the institution in charge of the coordination and management of this journal. This is the centre from where the call for papers will be launched for all the people interested in publishing their papers, always related to History, Archeology, Art History, Teaching History, etc. 


\section{Normas de Publicación}

El autor se compromete a enviar trabajos originales, que no se encuentren publicados en otras revistas ni en otros idiomas. Así mismo, el mismo artículo no podrá ser presentado en otras revistas mientras dure el proceso de evaluación.

\section{Envío y presentación de originales}

Los artículos se enviarán exclusivamente a través del correo electrónico a la dirección pantarei@um.es. Los textos serán enviados en formato DOC y las imágenes en formato JPEG o TIFF, y con un tamaño mínimo de 2000 px. Éstas no aparecerán incorporadas en el texto, sino enviadas en archivo aparte y correctamente numeradas según su posición en el texto. Junto al trabajo, se rellenará y enviará un documento aparte en el que se especifiquen los datos del autor siguiendo el modelo disponible en la página Web de la revista.

Para la redacción de los trabajos se tendrá en cuenta el Manual de la American Psychological Association, en su sexta edición. La extensión máxima de los trabajos será de 30 páginas. La tipografía será Arial 11, con interlineado sencillo y sin espacio alguno entre párrafos. El texto deberá ir justificado a ambos márgenes y sin sangría en los primeros párrafos. Los márgenes serán de $2,50 \mathrm{~cm}$. En los casos en los que fuera necesario incorporar notas, éstas irán a pie de página, enumeradas consecutivamente, con tipografía Arial 10, interlineado sencillo y justificadas a ambos márgenes.

Una información más detallada se encuentra disponible en la página http://www.um.es/cepoat/ pantarei.

\section{Proceso de valoración y evaluación}

Una vez recibidos los trabajos, la Revista realizará una primera valoración. Si el trabajo enviado se ajusta a las normas de presentación propuestas, la temática es coincidente con la línea editorial de la revista y posee la calidad científica necesaria, será remitido al consejo asesor para una primera evaluación. Si no es así en este primer paso se puede rechazar directamente los documentos que incumplan claramente la línea editorial.

Será el Consejo Asesor quien indique a la revista la originalidad, relevancia, estructura, redacción, aparato bibliográfico, etc. del trabajo enviado y, para ello, se designará a dos revisores expertos externos que evaluarán cada uno de los trabajos, que pueden formar parte (o no) de este Consejo Asesor. La selección de los revisores se ajustará a la temática y características metodológicas del trabajo. El nombre y filiación de los autores serán eliminados del trabajo para su revisión, así como los revisores actuarán de manera anónima y confidencial.

Los revisores deberán rellenar un informe de evaluación que centrará su atención en aspectos tales como características formales, originalidad y novedad de los trabajos, relevancia de las propuestas y los resultados, calidad metodológica y validez científica.

Una vez terminado el proceso se decidirá la aceptación o no de los mismos y su publicación en el número que sea pertinente, así como las modificaciones susceptibles de ser realizadas para su final publicación. Dicha notificación se enviará únicamente por correo electrónico, en un plazo máximo de seis meses. 


\section{Publishing rules}

The author is committed to submit original papers not having been published in other reviews or in other languages. In this way, it is not allowed for the same paper to be presented in other reviews during the evaluation process.

\section{Submission and presentation of originals}

The articles will be exclusively submitted by email to pantarei@um.es. The texts will be submitted in DOC format and the images in JPEG or TIFF format, and with a minimum size of 2000 px. Images will not be integrated in the text but sent in another file and properly numbered according to their position in the text. Attached to the paper, a document will be filled out and sent where the author's data will be specified following the model available on the website.

The sixth edition of the Manual of the American Psychological Association will be taken into account for the writing of the papers. The length of the papers must not exceed 30 pages. Typography will be Arial 11 , with simple line spacing and no space between paragraphs. The text must be justified on both margins without indentation in the first paragraphs. Margins size will be $2.50 \mathrm{~cm}$. Where it could be necessary the incorporation of notes, they will be at the bottom of the page, consecutively numbered with typography Arial 10, simple line spacing and justified on both margins.

More detailed information is available on the website: http://www.um.es/cepoat/pantarei.

\section{Examination and assessment process}

The Journal will submit the papers to a first examination once received. If the paper follows the presentation guidelines, the subject agrees with the editorial line of this journal, and possess the scientific quality required, it will be sent to the advisory council for a first assessment. If not, the documents which clearly fail to complete the editorial line may be rejected straightaway in this first step.

The Advisory Council will indicate the originality, relevance, structure, writing, bibliography, etc. of the text to the journal; for this purpose, two outside experts will be designated to review the papers; these experts can be (or not) part of this Advisory Council. The selection of the experts will adjust to the subject and methodological characteristics of the paper. Name and affiliation of the author will be eliminated from the text for its review, in this way experts will act anonymously and confidentially.

The experts will fill out an assessment report which will focus on aspects such as formal characteristics, originality and novelty of the papers, relevance and results of the proposal, methodological quality and scientific validity.

Once the process is finished, the acceptance or not of the papers and its publication in the corresponding edition will be decided, as well as the modifications that may be done for its final publication. This notification will be sent by email within 6 months maximum. 


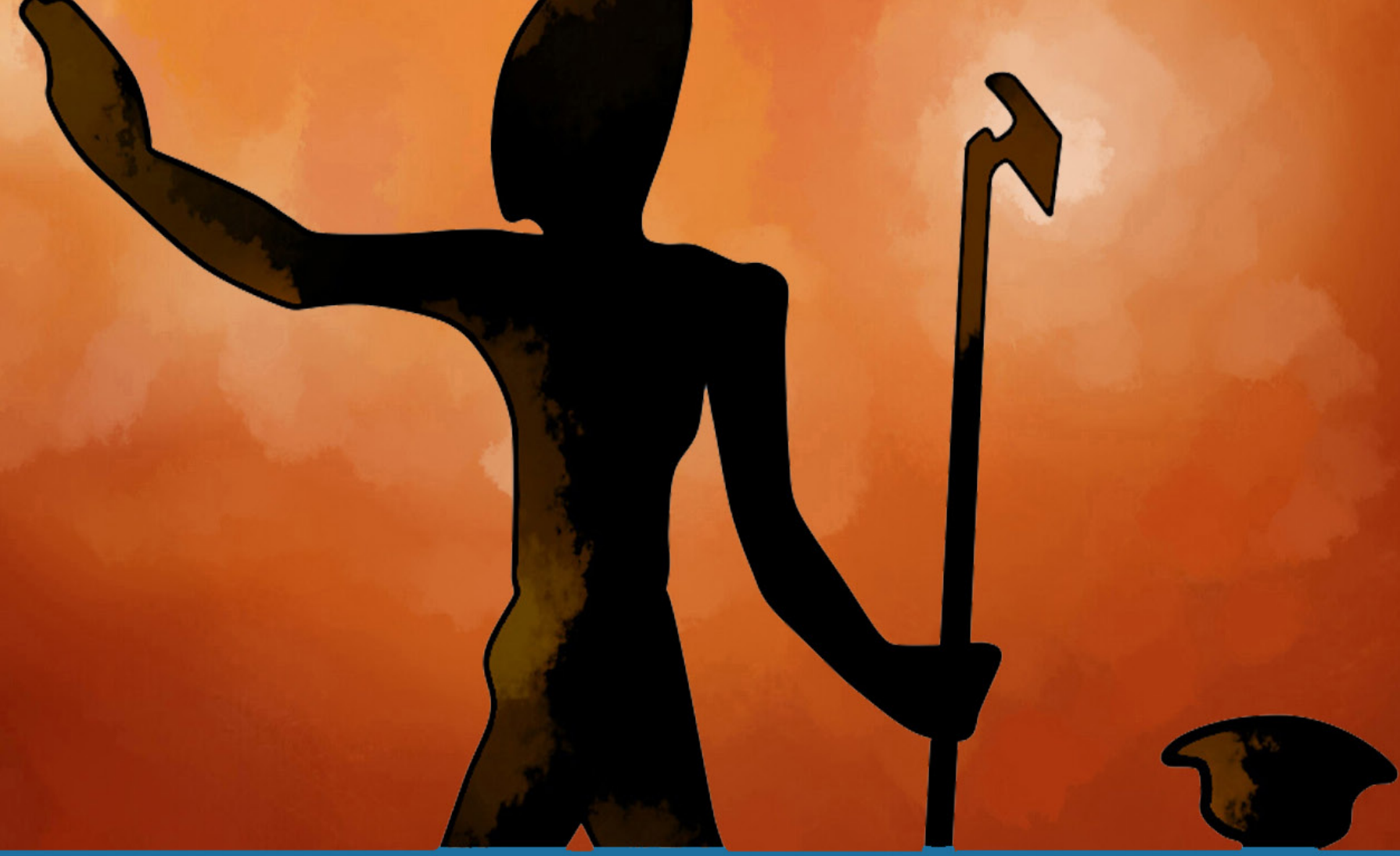

GepOA

centro de estudios de

próximo oriente y la

antigüedad tardía 